\title{
Justice under uncertainty
}

Citation for published version (APA):

Cettolin, E., \& Riedl, A. M. (2013). Justice under uncertainty. Maastricht University, Graduate School of Business and Economics. GSBE Research Memoranda No. 036 https://doi.org/10.26481/umagsb.2013036

Document status and date:

Published: 01/01/2013

DOI:

10.26481/umagsb.2013036

Document Version:

Publisher's PDF, also known as Version of record

\section{Please check the document version of this publication:}

- A submitted manuscript is the version of the article upon submission and before peer-review. There can be important differences between the submitted version and the official published version of record.

People interested in the research are advised to contact the author for the final version of the publication, or visit the DOI to the publisher's website.

- The final author version and the galley proof are versions of the publication after peer review.

- The final published version features the final layout of the paper including the volume, issue and page numbers.

Link to publication

\footnotetext{
General rights rights.

- You may freely distribute the URL identifying the publication in the public portal. please follow below link for the End User Agreement:

www.umlib.nl/taverne-license

Take down policy

If you believe that this document breaches copyright please contact us at:

repository@maastrichtuniversity.nl

providing details and we will investigate your claim.
}

Copyright and moral rights for the publications made accessible in the public portal are retained by the authors and/or other copyright owners and it is a condition of accessing publications that users recognise and abide by the legal requirements associated with these

- Users may download and print one copy of any publication from the public portal for the purpose of private study or research.

- You may not further distribute the material or use it for any profit-making activity or commercial gain

If the publication is distributed under the terms of Article $25 \mathrm{fa}$ of the Dutch Copyright Act, indicated by the "Taverne" license above, 


\section{Maastricht University}

Elena Cettolin, Arno Riedl

J ustice under uncertainty

RM/13/036

\section{GSBE}

Maastricht University School of Business and Economics

Graduate School of Business and Economics

P.O Box 616

NL- 6200 MD Maastricht

The Netherlands 


\title{
Justice under Uncertainty*
}

\author{
Elena Cettolin Arno Riedl
}

July 1,2013

\begin{abstract}
An important element for the public support of policies is their perceived justice. At the same time most policy choices have uncertain outcomes. We report the results of a first experiment investigating just allocations of resources when some recipients are exposed to uncertainty. Although, under certainty almost all uninvolved participants distribute resources equally, they exhibit remarkable heterogeneity in just allocations under uncertainty. Moreover, uninvolved participants allocate on average less to recipients exposed to higher degrees of uncertainty and allocations are correlated with their own risk preferences. The observed allocations are consistent with four different views of justice under uncertainty.
\end{abstract}

Keywords: Justice, uncertainty, experiment

JEL Classification: C91, D63

\footnotetext{
*Elena Cettolin: Department of Economics (AE1), Maastricht University, P.O.Box 616, 6200 MD Maastricht, the Netherlands, e.cettolin@maastrichtuniversity.nl; Arno Riedl (corresponding author): CESifo, IZA, Netspar, Department of Economics (AE1), Maastricht University, P.O.Box 616, 6200 MD Maastricht, the Netherlands, a.riedl@maastrichtuniversity.nl. We thank participants of seminars, conferences, and workshops at NHH Bergen, Bilkent University, ECARES Brussels, University of Jena, Loyola Marymount University, Maastricht University, ESEM Oslo, MPI Munich, CERGE-EI Prague, CalTech Pasadena, University of Pittsburgh, University of San Sebastian, and the Venice Summer Institute for many very valuable comments. The research documented in this paper was partly financed by the Oesterreichische Nationalbank (project number 11429) and also received financial support from the Netherlands Organisation for Scientific Research (NWO) (project number 400-09-451).
} 


\section{Introduction}

Uncertainty is an inevitable feature of most policy choices, as the ultimate outcome of a policy is often prone to events beyond the area of influence of the social decision maker. Moreover, in social decision making not only the possibility of random events have to be taken into account but also how a choice may impact the (relative) well-being of those affected by the policy. For example, a decision maker may have to decide between subsidizing and encouraging the use of a well tested safe vaccine and a new vaccine that with some probability will save more lives but may also induce strong adverse reactions (cf. Adler and Sanchirico 2006, p.282). A similar problem is also prominently present in the debate on organ allocation criteria. The 'maximum benefit criterion' proposes to rank potential organ donees according to their probability of survival after the transplant, whereas opponents argue that information on patients' mortality risk should not affect the ranking (Childress 2001).

In fact, policy decisions face the problem of uncertainty in almost any area where scarce resources should be allocated justly. For example, what is a just compensation scheme for civil servants occupying risky jobs (e.g., firefighters, police) relative to other safer positions? Or, what is the just allocation of resources between researchers proposing projects with relatively certain outcomes and researchers proposing projects with high benefit when lucky but low benefit when unlucky? In this paper we experimentally investigate the general question that underlies all these problems. What constitutes a just allocation when some recipients of resources are exposed to uncertainty?

The problem uncertainty introduces when considering just allocations can most clearly be exemplified for equally deserving recipients. Under certainty it seems natural that any just allocation would comprise an equal distribution of resources. However, when at least one of the recipients is faced with uncertainty different ideas of justice that have been discussed in the literature may lead to different just allocations 1 A utilitarian approach would allocate resources

\footnotetext{
${ }^{1}$ The problems studied in the extensive normative theoretical literature on how to assess social situations involving risk are not equivalent to the problem of just allocation of resources under uncertainty we consider. Nevertheless, the justice concepts of utilitarianism (e.g., Harsanvi 1955), ex ante egalitarianism (e.g., Diamond 1967, Larry G. Epstein 1992), and ex post egalitarianism (e.g., Adler and Sanchirico 2006) discussed in this literature provide important guidance in how to think about just allocations under uncertainty. See also Ben-Porath et al. (1997) and Gajdos and Maurin (2004) who propose a convex combination of an ex ante criterion and an ex post criterion and Fleurbaey (2010) who introduces the 'expected equally distributed equivalent' that also combines ex ante and ex post criteria.
} 
such that the sum of expected utilities is maximized but would be indifferent to the possibility of resulting inequalities. When the social decision maker has an aversion to inequality she may take on an ex ante or ex post view. In the ex ante view, focusing on initial symmetry of recipients, a just allocation would either equalize expected outcomes or expected utilities, depending on whether or not risk preferences of recipients are taken into account in the evaluation. In the ex post view, the distribution of actual outcomes determines how just the allocation is. Notably, when ex post redistribution is not feasible, the ex post outcomes can only be influenced by ex ante redistribution of resources. This brief discussion already illustrates that, when there is uncertainty, different views of justice will in general lead to different distributions of resources and utilities. Hence, conflicting ideas about justice under uncertainty could significantly impact the support for policies and affect public policy design. Arguably this conflict reaches beyond the public policy domain as it may impact (the perception of) decisions in firms, organizations and other economic environments where people may care about just allocations.

In this paper we report results of, to the best of our knowledge, the first experiment exploring just allocations when a recipient is exposed to various degrees of uncertainty. The experiment consisted of a production phase followed by an allocation phase. Participants were randomly divided into groups of three. In the production phase, in each group, two participants were engaged in a real effort task to produce a joint monetary output. The effort task was calibrated such that each participant in a pair produced the same share and, thus, was equally deserving in that respect. In the allocation phase, the third group member was put into the position of a social planner, henceforth called Benevolent Dictator (BD, Konow 2000), and was asked to distribute the money between the other two participants. The BD did not have any stakes in the monetary output and received a payment independent of her decision. Thus, the only incentive of a $\mathrm{BD}$ was to implement just allocations 23

\footnotetext{
${ }^{2}$ One may argue that the BD has actually no incentive to act justly but may instead make random decisions. This is certainly a possibility. However, as the elicitation of just choices requires by definition an uninvolved decision maker, in our opinion, the chosen implementation is as close as one can get to incentivizing just choices. Moreover, there are theoretical arguments and empirical facts that support the assumption that in the chosen set-up participants will indeed decide according to their view of justice. Theoretically, Konow (2000) and Karni and Safra (2002), for instance, argue that individuals suffer some disutility when actual allocations deviate from what they deem to be just and thus face an (intrinsic) incentive to act justly. Empirically, it is also found that the described procedure implements just choices (see, e.g., Konow 2000, Cappelen et al. 2013). Moreover, our results also indicate that BD's make just and not random choices (see Section 4.1).

${ }^{3}$ It is important to note that the implemented third-party impartiality procedure is not equivalent to the Rawlsian veil of ignorance (Rawls 1971), because BDs' earnings in the experiment are completely unrelated to
} 
Importantly, the BD had to make decisions in several allocation problems. In all problems, one recipient did not face uncertainty and earned exactly what was allocated to him. In contrast, the earnings of the other recipient were uncertain in all but one allocation problem. In problems characterized by uncertainty earnings could be larger or smaller than what was allocated. Across allocation problems we varied the level of uncertainty while keeping the expected value of a given allocation constant. In the final part of the experiment we elicited participants' risk preferences and their beliefs about the risk preferences of other participants in their group.

This design allows us to focus on our main conjectures and questions. When there is no uncertainty, we expect that participants in the role of BD choose the same just allocation, the equal split. However, do just allocations of different BDs also coincide when one recipient is exposed to uncertainty? Do just allocations change with the degree of uncertainty comprised by the different allocation problems? Are just allocations under uncertainty guided by principles of justice like utilitarianism, ex post or ex ante egalitarianism? Another question we can tackle with our design is whether or not just allocations are related to risk preferences of BDs or their beliefs about recipients risk preferences. In other words, do potential differences in observed just allocations of BDs 'merely' reflect differences in (perceived) risk preferences or could they reflect substantial disagreement regarding ideas of justice under uncertainty? Answers to these questions are important as adherence to different, perhaps conflicting, justice views, can substantially impact support for allocation and redistribution policies and public policy design.

Our main findings can be summarized as follows. First, we find that in the absence of uncertainty almost all BDs allocate resources exactly equally between recipients. We take this as evidence that (i) our procedure indeed elicits just allocations and that (ii) equal treatments of equals is the prevalent justice view under certainty. Second, just allocations under uncertainty exhibit substantial heterogeneity in each allocation problem. This shows that even when people implicitly agree on just allocations in certain environments they likely have conflicting justice views when uncertainty prevails. Third, just allocations respond to the degree of uncertainty and, on average, less is allocated to the recipient facing uncertainty the higher the degree of

their allocation decisions. We deliberately did not choose a 'behind the veil of ignorance' approach because it has been shown that the type of uncertainty entailed by the veil of ignorance influences individuals' allocation behavior by introducing insurance purposes (Aguiar et al. 2010, Schildberg-Hörisch 2010) and strategic considerations (Gerber et al. 2013). For experiments investigating the idea of the veil of ignorance empirically see the seminal work of Frohlich et al. (1987) and Frohlich and Oppenheimer (1990) and, e.g., Gerber et al. (2013) for recent evidence. 
uncertainty. Fourth, more risk averse BDs allocate more to the recipient facing uncertainty, whereas their beliefs about recipients' risk preferences seem not to guide choices. Finally, we also explore whether justice views derived from utilitarianism and egalitarianism can organize the observed just allocations. We find that a small majority of BDs make choices consistent with some form of ex ante equality but that utilitarian and ex post egalitarian views also find support. This plurality of justice views under uncertainty is consistent with a similar finding in the context of accountability by Cappelen et al. (2007).

Our paper builds on the tradition of empirical investigations of justice views initiated by the seminal paper of Yaari and Bar-Hillel (1984) (see also Kahneman et al. 1986). These early studies were employing surveys and vignettes and have led to a stream of papers using these methodologies that greatly improved our knowledge about peoples justice views (see, e.g., Schokkaert and Overlaet 1989, Schokkaert and Capeau 1991, Faravelli 2007 and Konow 2003, Tausch et al. 2013, for overviews).

Konow (2000) was the first to use incentivized experiments in justice research. He introduced a non-involved subject, the $\mathrm{BD}$, that was asked to allocate money to two anonymous recipients the joint product of their work. He finds that resources are less likely to be allocated in proportion to individuals' contributions when differences in productivity are random as compared to when they result from subjects' differential efforts. These results have been replicated by Dickinson and Tiefenthaler (2002) who contrast earned rights to non-earned ones in a more complex environment. Cappelen et al. (2007) also focus on individuals' justice ideas in situations involving production, but use allocation data from a standard dictator game. Their main finding is that when there are asymmetries between recipients there exists a plurality of justice ideas. In essence, these studies show that individuals are retained responsible for their outcomes whenever they can reasonably influence such outcomes. None of these studies allows for uncertain outcomes of allocation decisions.

Cappelen et al. (2013) comes perhaps closest to our study. They investigate the allocations of both non-involved subjects and stakeholders in situations where inequalities in output are the result of antecedent choices under risk. It appears that ex-post inequalities between risk takers and non-risk takers are mostly viewed as fair, but that inequalities between lucky and unlucky risk takers are eliminated. Although these authors allow for uncertainty their study substantially differs from ours. Whereas Cappelen et al. (2013) look for allocation decisions after uncertainty is resolved and, hence, the consequences of any redistribution decision are known with certainty, 
we study just allocations before uncertainty is resolved. Moreover, we study situations where recipients are equally deserving whereas the cited study looks at issues of merit.

Two interesting recent studies that also allow for risk in allocation decisions are Rohde and Rohde (2011) and Brock et al. (2013). In these papers the focus is on decisions of involved subjects who may or may not exhibit other-regarding preferences. The first study finds that even though people show concerns for inequality in a riskless setting they are little affected by the risk exposure of other subjects. The latter study finds that in a risky environment dictator giving is consistent with a mix of expected value comparisons and ex post considerations. Neither of these studies explores questions related to justice views.

The rest of the paper is organized as follows. In Section 2 we introduce the studied allocation problems and provide a theoretical framework for discussing justice under uncertainty. Section 3 describes the experimental design and procedures. Section 4 contains the results and Section 5 concludes. The instructions of the experiment are provided in the Appendix.

\section{General Set-Up and Theoretical Framework}

General set-up. In order to study views of justice in allocation problems with outcome uncertainty we explore various such problems, denoted by $m \in\{1, . . M\}$. In each allocation problem, an uninvolved third party has to divide between two recipients a monetary amount $X$ jointly produced by them. To isolate the effect of uncertainty the production task is calibrated such that equal contributions to the production of $X$ are (almost certainly) guaranteed. Moreover, anonymity of the uninvolved person as well as both recipients is ensured. Hence, the third party does not have any information about recipients' characteristics that would allow to discriminate between recipients, implying that they should be viewed as equally deserving 4

Recipients only differ in that one of them, for convenience called $U$, is exposed to uncertainty whereas the other, for convenience called $C$, faces certainty. Importantly, whether a recipient is exposed to uncertainty or not is beyond her influence. Specifically, in each allocation problem $m$ the uninvolved third party has to divide the amount $X$ between recipients $U$ and $C$, with $X=x_{U}+x_{C}$. Recipient $U$ 's final outcome depends on which of two possible events realizes after the allocation of $x_{U}$. The 'good' event $e$ realizes with probability $p$ in which case the amount $x_{U}$ allocated to $U$ is multiplied by $k>1$. With probability $1-p$ the 'bad' event $\bar{e}$ realizes, with the consequence that $x_{U}$ is multiplied by $\bar{k}(1>\bar{k} \geq 0)$.

\footnotetext{
${ }^{4}$ Under anonymity (symmetry) basically all theoretical rules of justice imply equality (see, e.g., Young 1995).
} 
Next to the effect of uncertainty per se we are also interested in how different degrees of uncertainty affect just allocations. Therefore, the investigated allocation problems differ in the likelihoods $(p, 1-p)$ of the good and bad events as well as in the consequences $(k, \bar{k})$ coupled with these events. In order to meaningfully compare allocations across different problems we have to ensure that they are not confounded by other motives, like material efficiency concerns. We achieve this by choosing $k, \bar{k}$, and $p$ such that in each allocation problem $m$ it holds that

$$
p x_{U} k+(1-p) x_{U} \bar{k}=x_{U} .
$$

Hence, in expectation $U$ receives exactly what is allocated to her in each allocation problem. This property ensures specifically that motivations related to risk exposure can not be confounded with expected material efficiency concerns when analyzing allocations decisions 5

The allocation problems are chosen such that for every concave utility function for money the expected utility of a given allocation $x_{U}$ to $U$ in problem $m$ is larger than the expected utility in problem $m+1$. Together with the fact that expected values stay constant (Equation (1)) this implies that the allocation problems can be ranked with respect to second-order stochastic dominance (Mas-Colell et al. 1995, p. 197). Accordingly, we will call allocation problem $m+1$ riskier than problem $m 6$ By varying the riskiness of $U$ 's final outcome in that way we can study whether just allocations are influenced by the dispersion of final outcomes.7

Theoretical framework. Scholars of distributive justice research invoked uncertainty as a means to discuss and rationalize justice principles (Rawls 1971, Konow 2003) and there is a long theoretical tradition discussing normative questions of how to assess social situations involving risk (see Section 1, Footnote 1 and the literature cited therein). The concepts proposed in this literature can not be transferred one-to-one to our allocation problems but we will use them as guidance in the theoretical ideas regarding just allocations under uncertainty, developed below.

\footnotetext{
${ }^{5}$ For the importance of material efficiency concerns in resource allocations, see Engelmann and Strobel (2004). With our assumption, we do no want to imply that expected material efficiency may not be interesting when investigating justice under uncertainty. quite to the contrary. However, as this is the first experimental study on justice under uncertainty we decided to keep the set-up free from potential influences due to other motives as good as possible.

${ }^{6}$ Details about parameter values chosen in the experiment are presented in Section 3 . The theoretical results derived below are independent of these specific parameter values.

${ }^{7}$ We also investigated two allocation problems characterized by ambiguity. For brevity we do not discuss them in the main text but present their characteristics and the corresponding results in Appendix C
} 
We first derive predictions based on three variations of the principle of 'equal treatment of equals' and then consider justice from a utilitarian perspective, which takes efficiency considerations into account.

The principle of 'equal treatment of equals' is relevant for the problems we study for two reasons. First, recipients can not be discriminated on the basis of any characteristic other than their exposure to uncertainty. Second, as exposure to uncertainty is exogenous and randomly assigned, recipients should not be held responsible for their position. However, equal treatment of equals can not straightforwardly be implemented because the presence of uncertainty impedes full equality in ex-post outcomes, that is in outcomes after uncertainty is resolved. Therefore, the implementation of the principle of equality is open to different interpretations. We propose three concepts that could be applied: equality in expected outcomes, equality in expected utilities, and equality in realized outcomes.

First, equality in expected outcomes can be defended as a principle of justice under uncertainty on the basis of equity considerations and the more recent idea of accountability (Konow 1996, 2003). Since in each allocation problem the expected value of an allocation is the allocation itself (cf. Equation (11) ) equality in expected outcomes implies splitting $X$ equally between the two recipients, in all allocation problems. That is,

$$
x_{U}=x_{C}=\frac{1}{2} X .
$$

This approach guarantees that $U$ and $C$ enjoy the same outcome in expected value. Therefore, we call it EV-equality.

Second, the justice idea of equality in expected utilities is related to Sen's (1997) Weak Equity Axiom which states that those in a disadvantaged position should be compensated (see also Rawls 1971). As most individuals are risk averse (Dohmen et al. 2009), recipients exposed to uncertainty can be considered to be disadvantaged and, hence, should be compensated by allocating them ex-ante more resources than individuals facing certainty.

Formally, allocations $x_{U}$ and $x_{C}$, satisfying equality of expected utilities $W(x), 8$ have to solve

$$
E\left[W\left(x_{U}\right)\right]=E\left[W\left(x_{C}\right)\right] \text { s.t. } x_{U}+x_{C}=X .
$$

In order to make quantitative predictions on allocations we assume that individuals can be characterized by a utility function for money $W(x)=x^{\alpha}$ that reflects their risk preferences

\footnotetext{
${ }^{8}$ Since from the viewpoint of the third party recipients do not differ in any aspects except for their exposure to uncertainty it is natural to assume that they are characterized by the same utility function.
} 
(Wakker 2010). Together with the definition of our allocation problems the above condition can be rewritten as

$$
p\left(x_{U} k\right)^{\alpha}+(1-p)\left(x_{U} \bar{k}\right)^{\alpha}=\left(x_{C}\right)^{\alpha} .
$$

Solving this equation with respect to $x_{U}$ and $x_{C}$ gives the just allocations

$$
x_{U}=\frac{1}{\exp \left(Z \alpha^{-1}\right)+1} X, \quad x_{C}=\frac{\exp \left(Z \alpha^{-1}\right)}{\exp \left(Z \alpha^{-1}\right)+1} X,
$$

where $Z=\ln \left[p(k)^{\alpha}+(1-p)(\bar{k})^{\alpha}\right]$. As this allocation of $X$ guarantees that $U$ and $C$ enjoy the same expected utility we call the corresponding justice idea EU-equality 9

From Equation (11) it follows that for all $\alpha \in] 0,1\left[, Z<0\right.$ and, hence, $\exp \left(Z \alpha^{-1}\right)<1$. Thus, for risk-averse recipients, the allocations in (3) imply that in all allocation problems characterized by uncertainty recipient $U$ should be allocated more than recipient $C$. Further, the just allocation to $U$ increases with the riskiness of the allocation problem, which follows from the fact that $Z$ is decreasing in the problems' riskiness.

The allocations in (3) are also just according to EU-equality when we assume that risk is positively valued (i.e., $\alpha>1$ ). In that case, $U$ should be allocated less than $C$ and the allocation to $U$ decreases with the riskiness of the allocation problem.

Third, equality can also be sought ex-post, that is after uncertainty has been resolved. This strictest form of outcome equality is related to the idea of egalitarianism (e.g., Deutsch 1985). With uncertainty, however, perfect equality is impossible to achieve and treating $U$ and $C$ equally ex post can be approximated by choosing allocations that minimize the expected difference between $U$ 's and $C$ 's final earnings. That is, allocations $x_{U}$ and $x_{C}$ have to satisfy

$$
\min _{x_{U}, x_{C}} p\left|k x_{U}-x_{C}\right|+(1-p)\left|\bar{k} x_{U}-x_{C}\right| \text { s.t. } x_{U}+x_{C}=X .
$$

The solution of the above minimization problem yields

$$
x_{U}=\frac{1}{k+1} X, \quad x_{C}=\frac{k}{k+1} X,
$$

which implies that the allocation to the recipient exposed to uncertainty is smaller than the allocation to the recipient facing certainty $(k>1$ in all allocation problems). We call this justice idea ex-post equality.

Note that, ex-post equal allocations do not depend on risk attitudes because the justice idea is applied after uncertainty is resolved. Therefore, the allocations in (4) are also just when the aim is to minimize (expected) utility differences, instead of outcome differences.

\footnotetext{
${ }^{9}$ The proofs of these and the other formal results in the main text are presented in Appendix $\mathrm{A}$
} 
The three justice principles discussed so far ignore efficiency considerations. Utilitarianism takes such considerations into account. It proposes to pursue the greatest aggregate level of utility, which implies that more resources should be allocated to the person that derives the greater utility from it. An important virtue of this criterion is that it selects an allocation on the utility efficiency frontier.

When recipients are identical and risk neutral the utilitarian principle does not select a unique allocation and any allocation of $X$ would be considered as just. However, if recipients are risk averse a given allocation yields less expected utility to $U$ than to $C$ and utilitarianism prescribes to allocate a smaller amount to $U$ than to $C$. Formally, the allocations $x_{U}$ and $x_{C}$ have to satisfy

$$
\max _{x_{U}, x_{C}} E\left[W\left(x_{U}\right)+W\left(x_{C}\right)\right] \text { s.t. } x_{U}+x_{C}=X,
$$

which, given our assumptions, is equivalent to

$$
\max _{x_{U}, x_{C}} p\left(x_{U} k\right)^{\alpha}+(1-p)\left(x_{U} \bar{k}\right)^{\alpha}+\left(x_{C}\right)^{\alpha} \text { s.t. } x_{U}+x_{C}=X
$$

and gives the just allocations

$$
x_{U}=\frac{1}{\exp \left(-Z(1-\alpha)^{-1}\right)+1} X, x_{C}=\frac{\exp \left(-Z(1-\alpha)^{-1}\right)}{\exp \left(-Z(1-\alpha)^{-1}\right)+1} X,
$$

with $Z=\ln \left[p(k)^{\alpha}+(1-p)(\bar{k})^{\alpha}\right]$. We call these just allocations utilitarian.

Note, that $\exp \left(-Z(1-\alpha)^{-1}\right)>1$ for all $\left.\alpha \in\right] 0,1[$ implies that in the just allocations given by (5), $U$ is allocated less than $C$. Further, it holds that the higher the riskiness of $U$ 's final earnings the less $U$ is allocated. If $\alpha>1$, that is when recipients are characterized by risk seeking preferences, the maximization of total welfare implies that all $X$ is allocated to $U$.

Table 1 summarizes the distributional implications of these four views of justice under uncertainty. It also shows the relation of just allocations to $U$ and $C$ in dependence of whether risk averse or risk seeking preferences are assumed.

\section{Experimental Design and Procedures}

The experiment consists of three parts: (1) the production of the resource $X$ by recipients $C$ and $U,(2)$ the just allocation of $X$ between by $C$ and $U$ by the uninvolved third-party ('Benevolent Dictator') $B D$, and (3) the elicitation of risk preferences, beliefs about risk preferences and other individual characteristics of all participants. In the following we describe the different parts in more detail. 
Table 1: Just Allocations under Uncertainty

\begin{tabular}{lccc}
\hline \hline & & \multicolumn{2}{c}{ Relation between $x_{U}$ and $x_{C}$} \\
\cline { 2 - 4 } & $x_{U}$ & Risk Averse & Risk Seeking \\
\hline EV-equality & $\frac{1}{2} X$ & $x_{U}=x_{C}$ & $x_{U}=x_{C}$ \\
EU-equality & $\frac{1}{\exp \left(Z \alpha^{-1}\right)+1} X$ & $x_{U}>x_{C}$ & $x_{U}<x_{C}$ \\
Ex-Post Equality & $\frac{1}{k+1} X$ & $x_{U}<x_{C}$ & $x_{U}<x_{C}$ \\
Utilitarian & $\frac{1}{\exp \left(-Z(1-\alpha)^{-1}\right)+1} X$ & $x_{U}<x_{C}$ & $x_{U}>x_{C}$ \\
\hline
\end{tabular}

Part 1: production of resource $X$. Each participant is randomly assigned a seat in a vision isolated cubicle equipped with a networked computer. After each participant has taken a seat, instructions for the first and second part of the experiment are distributed and read aloud by the experimenter. Participants are randomly matched into groups of three and assigned the role of either recipient $U$, recipient $C$, or third party $B D$. These roles are fixed throughout the experiment 10

In the first part of the experiment $U$ and $C$ work individually on a real effort task, while $B D$ is idle. The real effort task consists of the so-called 'slider task' introduced by Gill and Prowse (2012). In our version 32 sliders on horizontal bars are displayed on the computer screen. Using the mouse, each slider can be moved to any point of the bar and the actual position of a slider is displayed as a number between 0 and 100 to the right of the bar. The task is to position as many sliders as possible exactly in the middle of a bar. The slider is correctly positioned when the number 50 pops is displayed next up the slider 11 A recipient's score in the task, that is his productivity, is equal to the number of sliders positioned at 50 in 6 minutes time. During the task the achieved score and the remaining time are displayed at the top of the screen. We chose the slider task because it is easy to explain and understand, is identical across repetitions, and does not leave room for guessing.

The slider task is incentivized. For each correctly positioned slider $€ 0.25$ are credited, implying that each recipient can get credited up to $€ 8$. After the time for the task has expired, all three members of a group are informed about the productivity of $U$ and $C$ and, hence, the total amount of money generated, which is deposited in a group account. In order to minimize

\footnotetext{
${ }^{10}$ In the experiment subjects are assigned the neutral labels A, B, and C.

${ }^{11}$ Figure E.1 in Appendix E shows examples of the slider task.
} 
the likelihood of productivity differences we have chosen the number of sliders and the available time to complete the task such that maximum productivity can easily be achieved.

Part 2: just allocation of $X$. In this part of the experiment the $B D$ has to allocate the amount $X$ in the group account between $U$ and $C$, who are not active in this part. Since recipients $U$ and $C$ exerted effort in the first part, and are thus not mere money recipients, the $B D$ should be motivated to make a just allocation decision (Konow 2000). Importantly, the $B D$ does not have any stakes in the group account as her payment for the allocation task is independent of her decision and randomly determined at the end of the experiment. Specifically, the $B D$ can earn $4,6,10$ or 12 Euro with equal chance. We have chosen this payment procedure in order to maximize the likelihood that the third party's only incentive is to implement her normative just allocation. Further, we strove to minimize a potential experimenter demand effect regarding the equal division, by not including 8 as a possible outcome.

The $B D$ faces five allocation problems that satisfy the assumptions discussed above and are summarized in Table 2. The allocation problem 1-Certainty serves as a benchmark where the final earnings of both, $U$ and $C$, are not uncertain and thus equal to the amounts $x_{U}$ and $x_{C}$ allocated to them. In the other four allocation problems recipient $U$ is exposed to uncertainty while $C$ faces certainty. In 2-Risk recipient $U$ earns $k=1.5$ times what is allocated to her with probability $p=0.5$ and with probability $1-p=0.5$ she earns only half her allocation $(\bar{k}=0.5)$. The remaining allocation problems are constructed similarly. For instance, in 4-Risk $p=0.5$, $k=2$, and $\bar{k}=0$, implying that $U$ earns either twice what is allocated to her or nothing, both events having a chance of 50 percent. It is easy to see that expected earnings of $U$ are exactly $x_{U}$ in all allocation problems and that the spread of earnings, and hence riskiness, monotonically increases from allocation problem 1-Certainty to 5-Risk.

Table 2: Allocation problems.

\begin{tabular}{llc}
\hline \hline allocation problem & final earnings of $\mathrm{R}$ & final earnings of $\mathrm{C}$ \\
\hline 1-Certainty & $x_{U}$ & $x_{C}$ \\
2-Risk & $\left(0.5: x_{U} \cdot 1.5, x_{U} \cdot 0.5\right)$ & $x_{C}$ \\
3-Risk & $\left(0.8: x_{U} \cdot 1.25, x_{U} \cdot 0\right)$ & $x_{C}$ \\
4-Risk & $\left(0.5: x_{U} \cdot 2, x_{U} \cdot 0\right)$ & $x_{C}$ \\
5-Risk & $\left(0.2: x_{U} \cdot 5, x_{U} \cdot 0\right)$ & $x_{C}$ \\
\hline Note: $\left(p: x_{U} \cdot k, x_{U} \cdot \bar{k}\right)$ denotes the uncertain outcome $U$ is facing; $x_{U}+x_{R}=X$.
\end{tabular}


In the experiment, these allocation problems appear on the screen one by one and the order of appearance is randomized at the group level. Each $B D$ has to make an allocation decision in each problem. At the end of the experiment one problem is randomly selected to be relevant for payment of $U$ and $C$ and uncertainty is resolved by using a stack of cards numbered from 1 to 100. For instance, for an allocation problem where $U$ faces a 50 percent chance that her allocation is doubled this indeed happens if a card with a number smaller than 51 is drawn. The determination of earnings took place publicly at the end of the experiment so that subjects could witness how uncertainty was resolved. Subjects were informed about this procedure before they made any decisions.

Part 3: elicitation of individual characteristics. In the last part of the experiment we gather data on risk preferences, beliefs about risk preferences and other individual characteristics that could be related to allocations decisions of the $B D$. In order to measure risk preferences we elicit the certainty equivalents of six two outcomes lotteries (cf. Fehr-Duda et al. 2006). For each lottery subjects are asked to choose between the lottery and a number of sure payments 12 The parameters of the lotteries are chosen such that they allow to measure risk preferences for the same outcome ranges as used in the allocation problems. At the end of the experiment one decision is randomly selected to be relevant for payment and earnings are added to those of the first part.

We also elicit subjects' beliefs about others' risk preferences. For that purpose subjects have to estimate the choices of a randomly matched group member in four lotteries. This belief elicitation is incentivized with the interval scoring rule (Schlag and van der Weele 2009). Each participant is asked to indicate what $\mathrm{s} /$ he believes is the minimum and the maximum certainty equivalent of the matched participant for each lottery 13

At the end of third part of the experiment subjects are asked some socioeconomic questions and $B D$ 's are asked some questions regarding their decisions in the first part of the experiment. Thereafter subjects are privately payed out in cash and dismissed.

\footnotetext{
${ }^{12}$ The details of the used lotteries can be found in Table D.1 of Appendix D Certainty equivalents are calculated as the arithmetic mean of the smallest sure amount preferred to the lottery and the consecutive sure amount on the list. Subjects are forced to switch from the sure payment to the lottery only once, as consistency is crucial for the successive elicitation of beliefs about others' preferences.

${ }^{13}$ The interval scoring rule has two advantages compared to other belief elicitation procedures. First, it is less time consuming and less cognitively demanding then eliciting the probabilities over all possible events. Second, the interval scoring rule allows inferences that are valid under any degree of subjects' risk aversion and not only when subjects are risk neutral (Schlag and van der Weele 2009).
} 
The computerized experiment was conducted in the Behavioral and Experimental Economics lab (BEElab) at Maastricht University School of Business and Economics, using the z-tree software (Fischbacher 2007). In total 90 students from Maastricht University participated in the experiment. Most of them (82 percent) were enrolled in the School of Business and Economics and the rest came from a variety of studies, such as law, medicine and arts. 47 percent of the subjects were male and the average age was 23.5 years. An experimental session lasted approximately 80 minutes and the average earnings per subject were $€ 17$.

\section{Results}

In this section we first present descriptive statistics and statistical tests on BDs allocation behavior. We then proceed by analyzing the relationship between individuals' characteristics and allocations. Lastly, we estimate the distribution of theoretical justice ideas in our sample.

\subsection{Just Allocations under Uncertainty}

Our design of the production phase successfully induced maximum performance of both $U$ and $C$ in almost all of the 30 groups. Only in two groups maximum performance was not achieved. In the following analysis we exclude these two groups in order to rule out confounding effects on the allocation decisions of the $B D$ due to recipients' productivity differences. Consequently, for all analyzed groups the group account $X$ that has to be allocated equals $€ 16$.

To set the stage we consider first allocation problem 1-Certainty in which there is no uncertainty about final earnings. In this problem treating $U$ and $C$ equally unambiguously implies to split the group account in two equal shares, which is also efficient. Alternatively, as $B D$ s do not have stakes in the allocation, they may choose randomly in which case we should see widely dispersed allocation decisions. Therefore, the allocations observed in this problem also provide a test of whether our approach is successfully eliciting just allocations.

Figure 1 depicts the distribution of allocations to $U$ (that is, $x_{U}$ ). Except for two outliers, $B D$ s split the amount in the group account indeed equally between $U$ and $C$. This clearly demonstrates that (almost all of) our $B D$ s care about treating equally deserving individuals equally.

Result 1. When there is no uncertainty, just allocations amount to splitting the monetary output equally between recipients. 


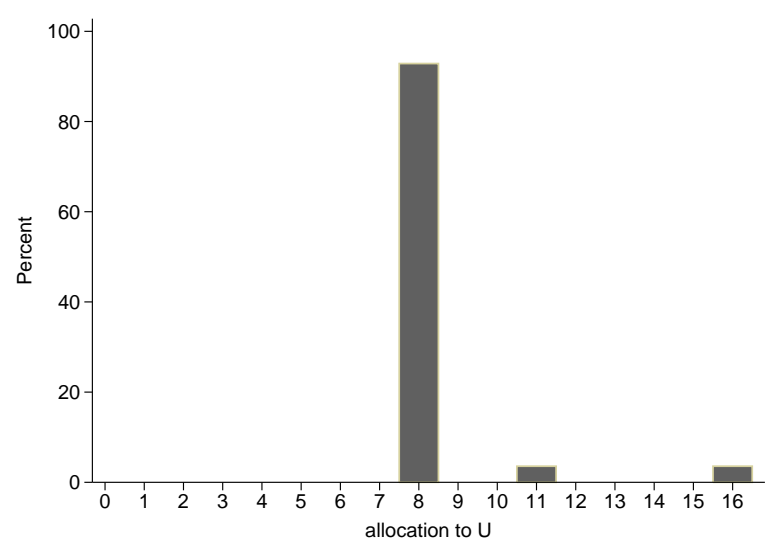

Figure 1: Allocations to recipient $U$ in 1-Certainty

Allocation behavior changes drastically in allocation problems with uncertainty. Figure 2 shows the distributions of allocations to recipient $U$ in allocation problems 2-Risk to 5-Risk. The distributions clearly indicate that just allocations differ across $B D \mathrm{~s}$ within each allocation problem as well as across allocation problems.

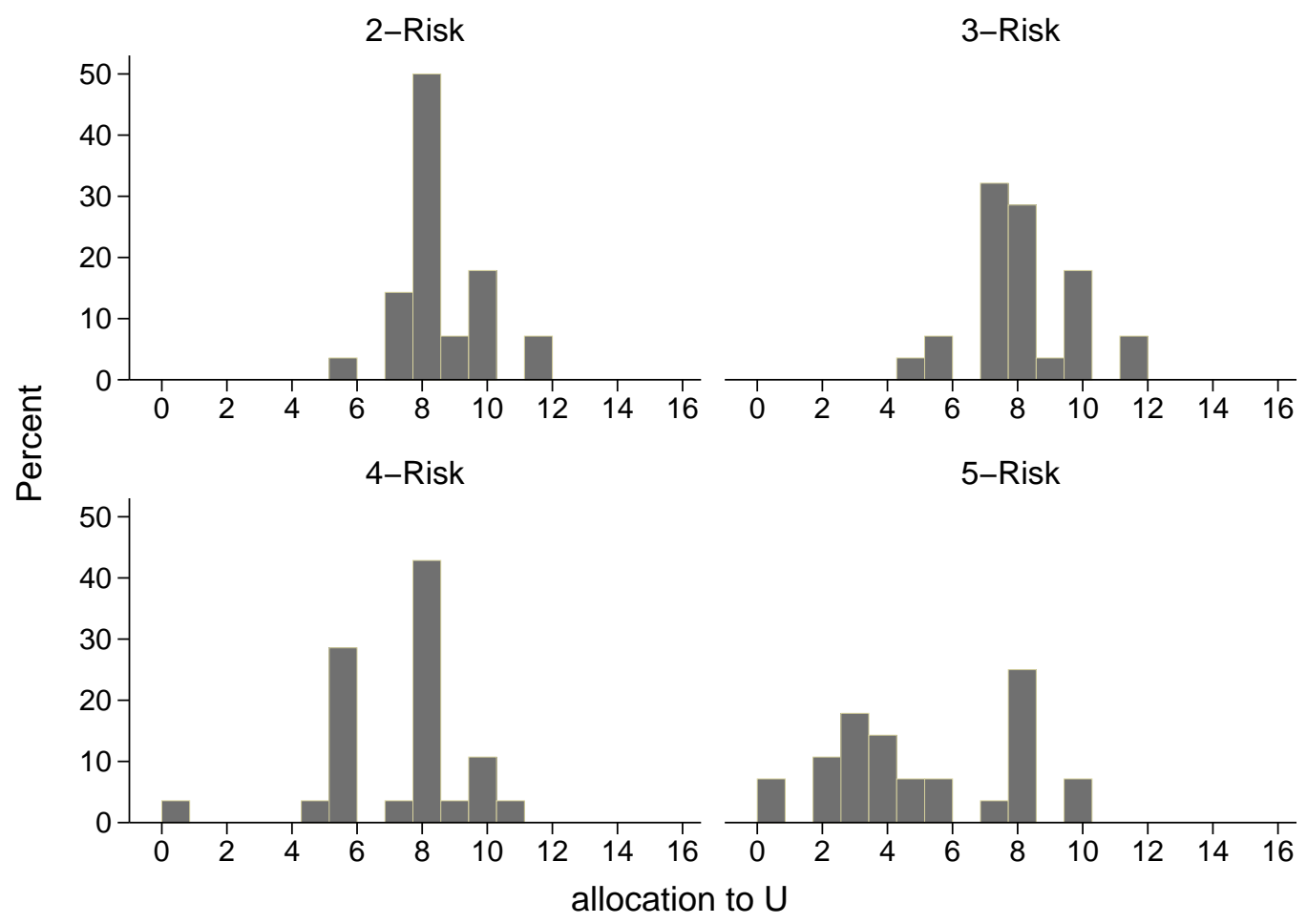

Figure 2: Allocations to recipient $U$ in allocations problems with uncertainty 
In the following we first test if for a given allocation problem the distribution of just allocations differs from the distribution where $X$ would be allocated equally between recipients, that is $x_{U}=x_{C}=8$. Thereafter, we test if distributions of just allocations differ across allocation problems.

Table 3: Allocations to recipient $U$

\begin{tabular}{lcccc}
\hline & \multicolumn{4}{c}{ allocation to $U$} \\
\cline { 2 - 5 } allocation problem & mean & st.dev. & WSR test & K-S test \\
\hline 1-Certainty & 8.39 & 1.59 & $\mathrm{p}=0.16$ & $\mathrm{p}=1.00$ \\
2-Risk & 8.50 & 1.43 & $\mathrm{p}=0.16$ & $\mathrm{p}=0.07$ \\
3-Risk & 8.13 & 1.69 & $\mathrm{p}=0.90$ & $\mathrm{p}=0.01$ \\
4-Risk & 7.33 & 2.10 & $\mathrm{p}=0.12$ & $\mathrm{p}=0.02$ \\
5-Risk & 5.10 & 2.84 & $\mathrm{p}=0.00$ & $\mathrm{p}=0.00$ \\
\hline
\end{tabular}

Note: WSR ... Wilcoxon signed-rank, K-S ... Kolmogorov-Smirnov; the nul hypothesis for both tests is that the true distribution is that all $B D \mathrm{~s}$ allocate 8 to recipient $U$.

Table 3 reports descriptive statistics and statistical tests regarding allocations to recipients $U 14$ Wilcoxon signed rank (WSR) tests reject the null hypothesis that the median allocation to $U$ is significantly different from 8 only in allocation problem 5 -Risk, where less is allocated to $U$ (Table 3 column 4). However, WSR tests pick up information only about differences in first moments and do not capture the large variety of allocations clearly visible in Figure 2, Therefore, for each allocation problem, we also employ Kolmogorov-Smirnov (K-S) tests to compare actual distributions to the hypothetical distribution where an equal split is uniformly chosen. We find that in all allocation problems with uncertainty the distribution of allocations is significantly different from uniformly choosing 8 . This holds at the 5 percent significance level, except for 2-Risk where $p=0.07$ (Table 3 column 5).

Result 2. In all allocation problems with uncertainty, allocations are widely dispersed and significantly different from the equal split.

The distributions depicted in Figure 2 also suggest that $B D$ s allocation decisions are related to the problems' riskiness, which increases from 2-Risk to 5-Risk. It is most pronounced for allocation problem 5-Risk which exhibits allocations that are clearly skewed toward giving less

\footnotetext{
${ }^{14}$ If not indicated otherwise all reported statistical tests are two-sided
} 
to the recipient facing uncertainty. To test this we compare all allocation problems pair-wise. Table 4 summarizes the results of these comparisons, where we correct for multiple testing using the 'false discovery rate' method (Benjamini and Hochberg 1995). The results show that, except for 2-Risk, distributions in all allocation problems with uncertainty differ significantly from 1-Certainty (Table 4, row 1-Certainty). Moreover, we observe significant differences between allocation problems characterized by uncertainty. Specifically, allocations in 5-Risk are significantly different from allocations in all other problems (Table 4, column 5-Risk). Together with the information on mean allocations (Table 3) we can conclude that allocations to recipient $U$ indeed are lower the higher the riskiness of the allocation problem.

Table 4: Pair-wise comparisons of allocation problems

\begin{tabular}{ccccc}
\hline \hline & 2-Risk & 3-Risk & 4-Risk & 5-Risk \\
\hline \multirow{2}{*}{ 1-Certainty } & $\mathrm{x}[\mathrm{x}]$ & $\mathrm{x}[* * *]$ & $*[* *]$ & $* * *[* * *]$ \\
\cline { 2 - 5 } & 2 2-Risk & $\mathrm{x}[\mathrm{x}]$ & $* *[\mathrm{x}]$ & $* * *[* * *]$ \\
\cline { 3 - 5 } & & 3-Risk & $\mathrm{x}[\mathrm{x}]$ & $* * *[* * *]$ \\
\cline { 3 - 4 } & & & 4 -Risk & $* * *[* * *]$ \\
\hline
\end{tabular}

Note: WSR [K-S] tests; an $\mathrm{x}$ indicates that there is no statistically significant differences. $* * *, * *, *$ indicates significance at the 1,5 , and 10 percent level, respectively.

Result 3. Just allocations to recipients exposed to uncertainty are lower the higher the riskiness of the allocation problem. Specifically, when these recipients' exposure to uncertainty is highest the amount allocated is significantly less than in all other allocation problems.

In the following we zoom in to the individual data and explore whether the variation in just allocations is related to variations in $B D$ s' risk preferences, their beliefs about others' risk preferences, and other characteristics we have elicited in Part 3 of the experiment. In order to estimate a subject's risk preference we use the certainty equivalents elicited in the lottery tasks and assume that subjects' preferences can be represented by a utility function for money $W(x)=x^{\alpha}$. We then estimate the value of $\alpha$ for each subject by minimizing the sum of squared distances between predicted and observed certainty equivalents (Wakker 2008, 2010) 15 The

\footnotetext{
${ }^{15}$ Formally, $\alpha$ is chosen such that
}

$$
\min _{\alpha} \sum_{i=1}^{6}\left[\left(p_{i} y_{i}^{\alpha}+\left(1-p_{i}\right) z_{i}^{\alpha}\right)^{\frac{1}{\alpha}}-c e_{i}\right]^{2},
$$


average estimated level of risk aversion of $B D$ s is moderate (mean $\alpha=0.77$, st.dev $=0.24$, median $\alpha=0.79$ ) and in keeping with the literature (Holt and Laury 2002) 16

In order to estimate subjects' beliefs about others' risk preferences we take the midpoints of the elicited intervals regarding others' certainty equivalents in the lottery tasks and employ the same method used for the estimation of risk preferences. We find that $B D$ s' beliefs about $U$ 's and $C$ 's risk preferences are on average close to their own risk preferences and imperfectly correlated with them (mean believed $\alpha=0.72$; Spearman's $\rho=0.61, p<0.001$; Pearson correlation coefficient $=0.48, p=0.01)$.

To understand whether $B D$ s' allocations are related to elicited individual characteristics we run an OLS regression with $x_{U}$ as dependent variable. As reported above, $B D$ s' own risk preferences and beliefs about recipients' risk preferences are correlated. Hence, we run a regression where we only included the $B D$ s 'believed $\alpha$ ' and another where we instead included the $B D$ s own $\alpha$. In the latter case the coefficient estimate of $\alpha$ is significant and in the former case the coefficient estimate of 'believed $\alpha$ ' is insignificant. Hence, we only report results where $\alpha$, but not the beliefs measure, is included in the regression. We also introduced a trend variable ('riskiness') that orders the allocation problems according to their riskiness and a dummy variable for gender ('female'), that takes value 1 for female and 0 for male $B D$ s. Table 5 reports the regression results. The significantly negative coefficient of 'riskiness' corroborates the finding reported above using non-parametric tests that $B D$ s allocation to $U$ decreases with the riskiness of the allocation problem. Further, allocations to $U$ are also negatively and significantly related to $B D$ 's own risk aversion 17 Hence, on average, the more risk averse a $B D$ is the more she allocates to recipient $U$. It appears that gender is not significantly related to $B D$ s allocations.

Result 4. Just allocations to recipients exposed to uncertainty significantly decrease with higher riskiness of the allocation problem. Moreover, just allocations are significantly positively related to $B D$ s' own aversion to risk. BDs gender and beliefs about recipients' risk attitudes are unrelated with their allocation decision.

where the first term in brackets indicates the theoretically predicted certainty equivalent for lottery $i$ and $c e_{i}$ is the elicited certainty equivalent of lottery $i$. To correct for heteroscedasticity lotteries are normalized to uniform length.

${ }^{16}$ Pair-wise comparisons of $B D \mathrm{~s}^{\prime}, U \mathrm{~s}^{\prime}$, and $C \mathrm{~s}^{\prime}$ risk attitudes do not detect any statistically significant differences (Mann-Whitney tests, $p \geq 0.14$ ).

${ }^{17}$ In the regression two outlier allocations equal to 0 made by an extremely risk averse $B D$ are excluded. When included, the coefficient of riskiness remains significant but alpha becomes insignificant. 
Table 5: Determinants of allocations to $U$

\begin{tabular}{lcc}
\hline \hline & \multicolumn{2}{c}{ dep. var.: allocation to $U$} \\
\cline { 2 - 3 } & Coefficient & (Std. Err.) \\
\hline riskiness & $-0.998^{* * *}$ & $(0.209)$ \\
alpha & $-1.877^{* *}$ & $(0.921)$ \\
gender & 0.191 & $(0.393)$ \\
intercept & $12.243^{* * *}$ & $(1.020)$ \\
$N$ & \multicolumn{2}{c}{110} \\
$R^{2}$ & \multicolumn{2}{c}{0.292} \\
$F_{(3,27)}$ & \multicolumn{2}{c}{9.74} \\
\hline
\end{tabular}

Note: ${ }^{* * *}\left({ }^{* *}\right)$ indicates significance at the $1(5)$ percent level; OLS regression; standard errors are robust to heteroskedasticity and are clustered on the 28 subjects.

\subsection{Views of Justice under Uncertainty}

In relation to the theoretical framework laid out in Section 2 the above results indicate that, on average, $B D$ s employ a utilitarian justice idea. Utilitarian allocations for risk averse recipients prescribe to allocate less to recipient $U$ than to recipient $C$ and also that allocations to $U$ decrease with higher riskiness of the allocation problem (see Table 1 and Equation (5) ). However, an important aspect of our data is the large variety in just allocations within each allocation problem. As this can only partly be explained by variations in risk aversion, it suggests that different $B D$ s have different ideas of just allocations as soon as uncertainty comes into play. In the following we use the theoretical just allocations derived in Section 2 and classify $B D$ s into corresponding justice types.

Just allocations based on EU-equality or utilitarianism depend on the risk preferences of recipient $U$ (see Table 1). Therefore, in order to calculate allocations for each justice view on an individual basis, we need to make assumptions on how risk preferences enter each $B D$ s allocation decisions. In the experiment $B D$ s do not know recipients' risk preferences, implying that they have to apply either their own risk attitudes or their beliefs about recipients' risk attitudes. In order to calculate predicted allocations for EU-equality and utilitarianism we assume that $B D$ s evaluate recipient $U$ 's position from their own viewpoint. That is, for each $B D$ we apply his/her estimated risk preference parameter $\alpha$. This seems reasonable given that $B D$ s' own 
risk preferences are related to their allocation decisions whereas their beliefs about recipients' risk preferences are not. Just allocations according to EV-equality and ex-post equality do only invoke material outcomes and are, thus, independent of risk attitudes (see Table 1).

After computing allocations according to each justice view at the individual level, we estimate which view best represents an individual's allocation decisions across all allocation problems. To this end, we calculate the squared distance between each allocation decision under uncertainty and the four theoretical just allocations. The justice view that minimizes the sum of squared residuals over all risky allocation problems is then considered to represent an individual's justice type. Formally, we estimate for each individual $B D_{i}$

$$
\min _{j} \sum_{m=2}^{5}\left(y_{i}^{m}-x_{i}^{j, m}\right)^{2},
$$

where $y_{i}^{m}$ is the actual amount allocated by $B D_{i}$ to recipient $U$ in allocation problem $m$ and $x_{i}^{j, m}$ is the amount recipient $U$ should receive in allocation problem $m$ according to justice view $j=\{$ EV-equality, EU-equality, ex-post equality, utilitarian $\}$ of $B D_{i}$.

Result 5. Of the BDs, 39 percent are best represented by EV-equality, 29 percent by utilitarianism, 18 percent by ex-post equality, and 14 percent by EU-equality 18

Hence, although on average utilitarianism best represents just allocations under uncertainty, this result shows that most $B D$ s are best represented by EV-equality that equalizes expected earnings of both recipients. Moreover, a non-negligible minority of 18 percent neglects ex-ante justice considerations and adopts an ex-post equality view. The smallest group is the one represented by EU-equality, which are basically those $B D$ s who give more to recipient $U$ than to recipient $C$ in all allocation problems. Next to providing a clear classification according to justice ideas under uncertainty this result also corroborates that - under uncertainty - ideas about how to justly treat recipients widely differ.

\section{Concluding Remarks}

Our study provides first empirical evidence on justice views when recipients of resources are exposed to different levels of uncertainty. A main insight from our experiment is that equally deserving recipients are treated very differently when one of them is exposed to uncertainty.

\footnotetext{
${ }^{18} \mathrm{It}$ is worth noting that as the mean squared error equals 3.08 and the median is only 1.36 the fit of our classification can be considered as rather good.
} 
Moreover, perhaps even more importantly, just allocations under uncertainty exhibit remarkable heterogeneity. This holds even though under certainty our uninvolved decision makers implicitly agree on the same just allocation, the equal split of resources. We also find that just allocations respond to the degree of uncertainty, as the higher uncertainty the less is allocated to the recipient exposed to it. Finally, social decision makers in our experiment are taking into account their own risk preferences but seem to ignore (their beliefs about) the risk preferences of recipients.

Although one has to be careful in drawing general conclusions from an experiment, our results suggest that heterogeneity in justice views may be part of an explanation for the regular occurrence of controversies surrounding allocation problems with uncertain outcomes. In health care, the public debate in Italy regarding the issue of whether or not taking into account health risks in the allocation of health resources is an example at hand (Simoes et al. 2012). Also public discussions as well as debates among medical ethics concerning just organ allocation policy could be related to different views of justice when uncertain outcomes prevail (Childress 2001, Persad et al. 2009). Other domains where our results could be informative about the public support of particular policies are the allocation of resources to curb poverty and fighting crime, and policy programs to reduce unemployment.

What our results also highlight is that, with uncertainty, even in the absence of self-interest or political ideology, there is not necessarily a consensus about the right policy to tackle societal or economical problems. Hence, in order to successfully implement even a benevolent policy it will be necessary to coordinate peoples views on the 'fairness' of the policy. Our study indicates that this may not always be easy to achieve as people with very similar socio-economic backgrounds already adhere to different justice views, ranging from utilitarianism to ex ante and ex post versions of egalitarianism.

We consider our study as a first step toward a better understanding of peoples view of just allocations and justice in general, when there is uncertainty about final outcomes. Naturally, many questions remain open that may provide interesting avenues for future research. In order to achieve clean comparisons, we have implemented a mean preserving spread when varying the degree of uncertainty. It would be interesting to explore whether our results generalize to other forms of uncertainty. Moreover, in order to avoid confounds, a special feature of our design is that recipients are equally deserving. In future research it would be interesting to investigate just allocation decisions under uncertainty when people are unequal at the outset. Our results could serve as a basis for predictions in these circumstances. Such research could explore the consequences of the combined pluralism of justice views under uncertainty we find 
with the pluralism of fairness ideals found by Cappelen et al. (2007), when there is certainty but different degrees of deservingness. In our study uncertainty is exogenous and it may be interesting to investigate how justice views change when combined with endogenously chosen risks (cf. Cappelen et al. 2013, Cettolin and Tausch 2013).

In our study we focused on justice views and, thus, on allocation decisions of uninvolved decision makers. It has been shown that when people have stakes in a distribution problem they tend to interpret fairness in a way that is beneficial for themselves (see, e.g. Babcock et al.|1995, Babcock and Loewenstein 1997, Gächter and Riedl 2005, Rodriguez-Lara and Moreno-Garrido 2012). Further, such self-serving biases seem to emerge especially when information on the relation between actions and outcomes can be selectively chosen or interpreted (Dana et al. 2006, 2007). Thus, an interesting extension of our study could be to investigate behavior of stakeholders who are exposed to risk (similar to, e.g., in Brock et al. 2013) and relate it to possibly self-serving interpretations of justice views. Our results on the prevalence and pluralism of views of justice under uncertainty provide a necessary first step for such investigations. 


\section{References}

Adler, M. D. and Sanchirico, C. W. (2006). Inequality and uncertainty: Theory and legal applications. University of Pennsylvania Law Review, 155(2):279-377.

Aguiar, F., Becker, A., and Miller, L. (2010). Whose impartiality? An experimental study of veiled stakeholders, impartial spectators and ideal observers. Jena Economic Research Papers, 2010:040.

Babcock, L. and Loewenstein, G. (1997). Explaining bargaining impasse: The role of self-serving biases. The Journal of Economic Perspectives, 11(1):109-126.

Babcock, L., Loewenstein, G., Issacharoff, S., and Camerer, C. (1995). Biased judgments of fairness in bargaining. American Economic Review, 85(5):1337-1343.

Ben-Porath, E., Gilboa, I., and Schmeidler, D. (1997). On the Measurement of Inequality under Uncertainty. Journal of Economic Theory, 75(1):194-204.

Benjamini, Y. and Hochberg, Y. (1995). Controlling the false discovery rate: A practical and powerful approach to multiple testing. Journal of the Royal Statistical Society Series B (Methodological), 57:289-300.

Brock, J. M., Lange, A., and Ozbay, E. Y. (2013). Dictating the risk: Experimental evidence on giving in risky environments. American Economic Review, 103(1):415-37.

Cappelen, A. W., Hole, A. D., Sørensen, E. Ø., and Tungodden, B. (2007). The pluralism of fairness ideals: An experimental approach. American Economic Review, 97(3):818-827.

Cappelen, A. W., Konow, J., Sørensen, E. Ø., and Tungodden, B. (2013). Just luck: An experimental study of risk taking and fairness. American Economic Review, 103(4):1398-1413.

Cettolin, E. and Tausch, F. (2013). Risk taking and risk sharing - Does responsibility matter? Mimeo, Department of Economics, Maastricht University.

Childress, J. F. (2001). Putting patients first in organ allocation: An ethical analysis of the U.S. debate. Cambridge Quarterly of Healthcare Ethics, 10(4):365-376.

Dana, J., Cain, D. M., and Dawes, R. M. (2006). What you don't know won't hurt me: Costly (but quiet) exit in dictator games. Organizational Behavior and Human Decision Processes, 100(2):193-201. 
Dana, J., Weber, R. A., and Kuang, J. X. (2007). Exploiting moral wiggle room: Experiments demonstrating an illusory preference for fairness. Economic Theory, 33(1):67-80.

Deutsch, M. (1985). Distributive justice: A social-psychological perspective. Yale University Press, New Haven, CT.

Diamond, P. A. (1967). Cardinal Welfare, Individualistic Ethics, and Interpersonal Comparison of Utility: Comment. Journal of Political Economy, 75(5):765-766.

Dickinson, D. L. and Tiefenthaler, J. (2002). What is fair? Experimental evidence. Southern Economic Journal, pages 414-428.

Dohmen, T., Falk, A., Huffman, D., Sunde, U., Schupp, J., and Wagner, G. G. (2009). Individual risk attitudes: Measurement, determinants and behavioral consequences. Research Memoranda 007, Maastricht : ROA, Research Centre for Education and the Labour Market.

Engelmann, D. and Strobel, M. (2004). Inequality aversion, efficiency, and maximin preferences in simple distribution experiments. American Economic Review, 94(4):857-869.

Faravelli, M. (2007). How context matters: A survey based experiment on distributive justice. Journal of Public Economics, 91(7-8):1399-1422.

Fehr-Duda, H., de Gennaro, M., and Schubert, R. (2006). Gender, financial risk, and probability weights. Theory and Decision, 60:283-313.

Fischbacher, U. (2007). z-tree: Zurich toolbox for ready-made economic experiments. Experimental Economics, 10:171-178.

Fleurbaey, M. (2010). Assessing Risky Social Situations. Journal of Political Economy, 118(4):649-680.

Frohlich, N. and Oppenheimer, J. A. (1990). Choosing justice in experimental democracies with production. American Political Science Review, 84(2):461-477.

Frohlich, N., Oppenheimer, J. A., and Eavey, C. L. (1987). Choices of principles of distributive justice in experimental groups. American Journal of Political Science, 31(3):606-637.

Gächter, S. and Riedl, A. (2005). Moral property rights in bargaining with infeasible claims. Management Science, 51(2):249-263. 
Gajdos, T. and Maurin, E. (2004). Unequal uncertainties and uncertain inequalities: An axiomatic approach. Journal of Economic Theory, 116(1):93-118.

Gerber, A., Nicklisch, A., and Voigt, S. (2013). Strategic choices for redistribution and the veil of ignorance: Theory and experimental evidence. Working Paper. Department of Economics, University of Hamburg.

Gill, D. and Prowse, V. L. (2012). A structural analysis of disappointment aversion in a real effort competition. American Economic Review, 102(1):469-503.

Harsanyi, J. C. (1955). Cardinal Welfare, Individualistic Ethics, and Interpersonal Comparisons of Utility. Journal of Political Economy, 63(4):309-321.

Holt, C. and Laury, S. (2002). Risk aversion and incentive effects. American Economic Review, 92(5):1644-1655.

Kahneman, D., Knetsch, J., and Thaler, R. (1986). Fairness as a constraint on profit seeking: Entitlements in the market. American Economic Review, 76(4):728-741.

Karni, E. and Safra, Z. (2002). Individual sense of justice: A utility representation. Econometrica, 70(1):263-284.

Konow, J. (1996). A positive theory of economic fairness. Journal of Economic Behavior and Organization, 31(1):13-35.

Konow, J. (2000). Fair shares: Accountability and cognitive dissonance in allocation decisions. American Economic Review, 90(4):1072-1091.

Konow, J. (2003). Which is the fairest one of all? A positive analysis of justice theories. Journal of Economic Literature, 41(4):1188-1239.

Larry G. Epstein, U. S. (1992). Quadratic Social Welfare Functions. Journal of Political Economy, 100(4):691-712.

Mas-Colell, A., Whinston, M. D., and Green, J. R. (1995). Microeconomic Theory. Oxford University Press, Oxford, UK.

Persad, G., Wertheimer, A., and Emanuel, E. J. (2009). Principles for allocation of scarce medical interventions. The Lancet, 373(9661):423-431. 
Rawls, J. (1971). A Theory of Justice. Oxford University Press, Oxford, UK.

Rodriguez-Lara, I. and Moreno-Garrido, L. (2012). Self-interest and fairness: Self-serving choices of justice principles. Experimental Economics, 15(1):158-175.

Rohde, I. M. and Rohde, K. M. (2011). Risk attitudes in a social context. Journal of Risk and Uncertainty, 43(3):205-225.

Savage, L. J. (1954). The Foundations of Statistics. Wiley, New York.

Schildberg-Hörisch, H. (2010). Is the veil of ignorance only a concept about risk? An experiment. Journal of Public Economics, 94(11-12):1062-1066.

Schlag, K. H. and van der Weele, J. (2009). Efficient interval scoring rules. Universitat Pompeu Fabra Working Paper 1176.

Schokkaert, E. and Capeau, B. (1991). Interindividual differences in opinions about distributive justice. Kyklos, 44(3):325-515.

Schokkaert, E. and Overlaet, B. (1989). Moral intuitions and economic models of distributive justice. Social Choice and Welfare, 6(1):19-31.

Sen, A. (1997). On economic inequality. Oxford University Press, Oxford, UK.

Simoes, E., Mariotti, S., Rossi, A., Heim, A., Lobello, F., Mokdad, A., and Scafato, E. (2012). The Italian health surveillance (SiVeAS) prioritization approach to reduce chronic disease risk factors. International Journal of Public Health, 57(4):719-733.

Tausch, F., Potters, J., and Riedl, A. (2013). Preferences for redistribution and pensions. What can we learn from experiments? Jouranl of Pension Economics and Finance. forthcoming.

Wakker, P. (2008). Explaining the characteristics of the power (CRRA) utility family. Health Economics, 17:1329-1344.

Wakker, P. (2010). Prospect Theory for Risk and Ambiguity. Cambridge University Press, Cambridge, UK.

Yaari, M. E. and Bar-Hillel, M. (1984). On dividing justly. Social Choice and Welfare, 1(1):1-24.

Young, H. P. (1995). Equity: In Theory and Practice. Princeton University Press, Princeton, NJ. 


\section{Appendix}

\section{A Just Allocations under Uncertainty: Analytical Derivations}

Here we formally derive the just allocations according to the fairness views EU-equality, ex-post equality, and utilitarianism, respectively, discussed in Section 2 of the main text.

\section{A.1 EU-equality}

EU-equality requires equalization of expected utilities, that is

$$
E\left[W\left(x_{U}\right)\right]=E\left[W\left(x_{C}\right)\right] \text { s.t. } x_{U}+x_{C}=X .
$$

Assuming $W(x)=x^{\alpha}$, using the definition of our allocation problems (see equation (11) in the main text) and substituting the constraint we can rewrite the previous equations as

$$
\begin{aligned}
p\left(x_{U} k\right)^{\alpha}+(1-p)\left(x_{U} \bar{k}\right)^{\alpha} & =\left(X-x_{U}\right)^{\alpha} \\
\Leftrightarrow & \\
\ln x_{U}^{\alpha}+\ln \left(p k^{\alpha}+(1-p) \bar{k}^{\alpha}\right) & =\ln \left(X-x_{U}\right)^{\alpha} .
\end{aligned}
$$

Define $Z:=\ln \left[p k^{\alpha}+(1-p) \bar{k}^{\alpha}\right]$ and rewrite the previous equation to

$$
\begin{gathered}
\alpha \ln x_{U}+Z=\alpha \ln \left(X-x_{U}\right) \\
\Leftrightarrow \\
\frac{X}{x_{U}}-1=\exp \left(Z \alpha^{-1}\right),
\end{gathered}
$$

which after some more rearrangements gives the just allocations to $U$ and $C$ as

$$
x_{U}^{E U-e q}=\frac{1}{\exp \left(Z \alpha^{-1}\right)+1} X, \quad x_{C}^{E U-e q}=\frac{\exp \left(Z \alpha^{-1}\right)}{\exp \left(Z \alpha^{-1}\right)+1} X .
$$

\section{A.2 Ex-post equality}

Ex-post equality requires the minimization of inequality after uncertainty has been resolved, that is, using the definition of our allocation problems (see equation (11) in the main text),

$$
\min _{x_{U}, x_{C}} p\left|k x_{U}-x_{C}\right|+(1-p)\left|\bar{k} x_{U}-x_{C}\right| \quad \text { s.t. } x_{U}+x_{C}=X
$$


Substituting the constraint, the minimization problem becomes

$$
\left.\min _{x_{U}} p \mid x_{U}(k+1)-X\right)|+(1-p)| x_{U}(\bar{k}+1)-X \mid .
$$

In order to find the minimizing $x_{U}$ we have to distinguish three cases.

case $1 \quad x_{U} \geq \frac{X}{\bar{k}+1} \quad\left(\Rightarrow x_{U} \geq \frac{X}{k+1}\right):$

That is, $\left.\min _{x_{U}} p\left[x_{U}(k+1)-X\right)\right]+(1-p)\left[x_{U}(\bar{k}+1)-X\right]:$

$$
\begin{gathered}
\frac{\partial}{\partial x_{U}}=p(k+1)+(1-p)(\bar{k}+1)>0 \Rightarrow \\
x_{U}=\frac{X}{\bar{k}+1} \text { minimizes the function. }
\end{gathered}
$$

case $\left.2 \quad x_{U} \leq \frac{X}{k+1} \quad \Rightarrow x_{U} \leq \frac{X}{\bar{k}+1}\right)$ :

That is, $\left.\min _{x_{U}} p\left[X-x_{U}(k+1)\right)\right]+(1-p)\left[X-x_{U}(\bar{k}+1)\right]:$

$$
\begin{gathered}
\frac{\partial}{\partial x_{U}}=-p(k+1)-(1-p)(\bar{k}+1)<0 \Rightarrow \\
x_{U}=\frac{X}{k+1} \text { minimizes the function. }
\end{gathered}
$$

case $3 \quad \frac{X}{k+1} \leq x_{U} \leq \frac{X}{\bar{k}+1}$ :

That is, $\min _{x_{U}} p\left[x_{U}(k+1)-X\right]+(1-p)\left[X-x_{U}(\bar{k}+1)\right]:$

$$
\begin{array}{r}
\frac{\partial}{\partial x_{U}}=p(k+1)-(1-p)(\bar{k}+1), \\
\frac{\partial}{\partial x_{U}}>0 \text { because } \frac{p}{1-p}>\frac{\bar{k}+1}{k+1} \forall p, k, \bar{k} \\
\text { and } x_{U}=\frac{X}{k+1} \text { minimizes the function. }
\end{array}
$$

Since the function to minimize is continuous in $x_{U}$, increasing for $x_{U} \geq \frac{X}{k+1}$ and decreasing for $x_{U} \leq \frac{X}{k+1}$, it follows that the global minimum is obtained at $\frac{X}{k+1}$. Therefore, the just allocations under ex-post equality are given by

$$
x_{U}^{e x-\text { posteq }}=\frac{1}{k+1} X, \quad x_{C}^{\text {ex-posteq }}=\frac{k}{k+1} X .
$$




\section{A.3 Utilitarianism}

Utilitarianism requires the maximization of the expected sum of utilities, that is

$$
\max _{x_{U}, x_{C}} E\left[W\left(x_{U}\right)+W\left(x_{C}\right)\right] \text { s.t. } x_{U}+x_{C}=X
$$

Again, assuming $W(x)=x^{\alpha}$, using the definition of our allocation problems (see equation (11) in the main text) and substituting the constraint we can rewrite the maximization problem as

$$
\max _{x_{U}} p\left(x_{U} k\right)^{\alpha}+(1-p)\left(x_{U} \bar{k}\right)^{\alpha}+\left(X-x_{U}\right)^{\alpha} .
$$

For $0<\alpha<1$ the function is concave and the first order condition is given by

$$
\begin{aligned}
\frac{\partial}{\partial x_{U}}= & \alpha p k\left(x_{U} k\right)^{\alpha-1}+(1-p) \alpha \bar{k}\left(x_{U} \bar{k}\right)^{\alpha-1}-\alpha\left(X-x_{U}\right)^{\alpha-1}=0 \\
& \Leftrightarrow \ln x_{U}^{\alpha-1}+\ln \left(p k^{\alpha}+(1-p) \bar{k}^{\alpha}\right)=\ln \left(X-x_{U}\right)^{\alpha-1}
\end{aligned}
$$

Define $Z:=\ln \left[p k^{\alpha}+(1-p) \bar{k}^{\alpha}\right]$ and rewrite the previous equation to

$$
\ln x_{U}^{\alpha-1}+Z=\ln \left(X-x_{U}\right)^{\alpha-1} \Leftrightarrow \frac{X}{x_{U}}-1=\exp \left(-Z(1-\alpha)^{-1}\right),
$$

which after some more rearrangements gives the just allocations for risk averse recipients as

$$
x_{U}^{u t i l}=\frac{1}{\exp \left(-Z(1-\alpha)^{-1}\right)+1} X, \quad x_{C}^{u t i l}=\frac{\exp \left(-Z(1-\alpha)^{-1}\right)}{\exp \left(-Z(1-\alpha)^{-1}\right)+1} X .
$$

When considering risk seeking recipients $(\alpha>1)$ the function to maximize is convex and, thus, the solution to the maximization problem is

$$
x_{U}^{u t i l}=X, \quad x_{C}^{u t i l}=0 .
$$




\section{B Answers to Debriefing Questionnaire}

In the following we provide some examples of answers provided by Benevolent Dictators in the debriefing questionnaire, where they were asked to shortly explain their allocation decisions. Answers are grouped into categories that correspond to the theoretically identified justice views.

Examples of answers related to EV-equality:

"I wanted to give B and $\mathrm{C}$ what they earned in their assignment, so 8 per person. $50 \%$ chance of 16 Euro and $50 \%$ chance of 0 Euro will also lead to a average earning of 8 (when repeating it very often)"

"Both scored the same amount of money. I did not want to punish $\mathrm{C}$ for being selected as C"

"I always allocated 8 because I thought this was most fair for $\mathrm{C}$ who always got the amount allocated. $\mathrm{C}$ earned 8 so I thought it was good to always grant him that amount. B had some random events that also influenced his earnings but since I could not influence those, I didn't take it into account"

Examples of answers related to EU-equality:

"tried to give B a bit more as he has the risk."

"compensate B with a higher amount to compensate the risk of him getting 0"

"Since B takes a higher risk, he/she deserves a higher payout to remedy the risk he/she takes"

Examples of answers related to ex-post equality:

"Since it would be either 5 times the amount or nothing I wanted to let the amount that B could earn be equal that of $\mathrm{C}$. So I gave 3 points to B (so that this person could earn 15 Euro) and the remaining 13 to C. This way the least amount of points was 'wasted' and could lead to an equal distribution."

"in case B is rewarded with money, the amount will be multiplied by 5 . I chose this distribution in order for everyone to have almost the same outcome"

"My aim was that if B wins, B won't earn much more than C." 
Examples of answers related to utilitarianism:

"Since B has greater possibilities to get 0. I allocate more to C."

"The chance was low for B to win, therefore more money to C." 


\section{Allocation Problems Characterized by Ambiguity}

The experiment also included two allocation problems characterized by ambiguity, shown in Table C.1, where the unknown probability is indicated by $p$.

Table C.1: Allocation problems under Ambiguity

\begin{tabular}{ccc}
\hline \hline allocation problem & final earnings of $U$ & final earnings of $C$ \\
\hline 6-Ambiguity & $\left(p: x_{U} \times 1.5, x_{U} \times 0.5\right)$ & $x_{C}$ \\
7-Ambiguity & $\left(p: x_{U} \times 2, x_{U} \times 0\right)$ & $x_{C}$ \\
\hline
\end{tabular}

In order to operationalize ambiguity in the laboratory a stack of 100 cards colored black and red is used. Neither the participants nor the experimenter know the exact color composition of the stack, and each participant is free to choose his/her winning color at the beginning of the experiment.

Table C.2 shows descriptive statistics and statistical test on BDs' allocations in the presence of ambiguity. An interesting aspect of the allocations in 6-Ambiguity and 7-Ambiguity is that

Table C.2: Allocations in ambiguous allocation problems

\begin{tabular}{lccccc}
\hline \hline & \multicolumn{5}{c}{ allocation to $U$} \\
\cline { 2 - 6 } allocation problem & mean & median & st. dev. & WSR test & K-S test \\
\hline 6-Ambiguity & 8.36 & 8 & 1.75 & $\begin{array}{l}\mathrm{z}=0.99 \\
(\mathrm{p}=0.32)\end{array}$ & $\mathrm{p}=0.03$ \\
7-Ambiguity & 7.73 & 8 & 2.39 & $\begin{array}{l}\mathrm{z}=-1.24 \\
(\mathrm{p}=0.21)\end{array}$ & $\mathrm{p}=0.03$ \\
\hline
\end{tabular}

Note: WSR ... Wilcoxon signed-rank, K-S ... Kolmogorov-Smirnov; the nul hypothesis for both tests is that the true distribution is that all $B D \mathrm{~s}$ allocate 8 to recipient $U$.

they do not differ from allocations in 2-Risk and 4-Risk, respectively (WSR tests). Given that these pairs of prospects are characterized by the same potential outcomes, this result suggests that Benevolent Dictators treat ambiguity no differently than a 50-50 prospect. 


\section{Risk Preference and Ambiguity Attitudes Elicitation Tasks}

Table D.1 shows the lotteries used in the risk preferences elicitation task described in Section 3 (Part 3) of the main text.

In addition to risk preferences we also elicited subjects' ambiguity attitudes. To this end, subjects faced six decision screens where they made choices between an ambiguous lottery and several risky ones. Both the ambiguous and the risky lotteries in a given decision screen were characterized by the same outcome pair, which are those in Table D.1.

Table D.1: Lotteries

\begin{tabular}{cccc}
\hline \hline Lottery & $p_{1}$ & $x_{1}$ & $x_{2}$ \\
\hline 1 & 0.20 & 40 & 0 \\
2 & 0.50 & 16 & 0 \\
3 & 0.80 & 10 & 0 \\
4 & 0.50 & 12 & 4 \\
5 & 0.25 & 16 & 4 \\
6 & 0.33 & 12 & 0 \\
\hline $\begin{array}{l}\text { Note: lotteries used in risk } \\
\text { preferences and ambiguity } \\
\text { attitudes elicitation tasks; } p_{1} \\
\text { denotes the probability }\end{array}$ of \\
winning $€ x_{1}$.
\end{tabular}

As in the first part of the experiment, ambiguity was generated with a deck of red and black cards in unknown color composition. On each screen subjects saw a description of the ambiguous lottery and a list of 20 risky lotteries. The first and the last risky lottery on the list were both degenerate and guarantee, respectively, the high and the low outcome of the lottery. From row to row in the list the likelihood of the high outcome decreased by $5 \%$, while the likelihood of the low outcome increased by $5 \%$. In each decision screen, subjects could switch only once from the risky to the ambiguous lottery.

Assuming subjective expected utility theory (Savage 1954), a subject's switching point reveals the bounds of the probability interval containing her prior belief on the ambiguous event. We take the midpoint of the interval to be the prior belief. (As the length of the interval is always equal to 0.05 taking the midpoint cannot result in a large bias.) Since the ambiguous event is the same on all decision screens, subjects should consistently reveal the same prior belief in all decisions. Pair- 
wise comparisons of elicited prior beliefs show that subjects indeed hold largely consistent beliefs ( $p \geq 0.22$ Wilcoxon signed-rank test). Thus, for each subject we can construct a variable called "prior-belief" defined as the average of the prior beliefs elicited from the six decision screens. The mean prior-belief of Benevolent Dictators is equal to 0.46 (st.dev. $=0.08$, median prior belief $=$ 0.48), which indicates only a slight aversion to ambiguity. Notably the standard deviation of prior-belief is very small, indicating very similar prior beliefs among Benevolent Dictators. Pairwise comparisons of BD's, R's and C's prior beliefs reveal no statistically significant difference between them ( $p \geq 0.69$, Mann-Whitney tests).

We also investigate subjects' beliefs about others' ambiguity preferences by asking subjects to estimate the choices made by a randomly matched group member for two ambiguous decision screens. The belief elicitation is incentivized with the interval scoring rule (Schlag and van der Weele 2009). We use the average of the two elicited believed prior beliefs to get a measure of Benevolent Dictators' belief about others' ambiguity attitudes, where ambiguity is disliked more the smaller the prior belief on the ambiguous event. We find that Benevolent Dictators' beliefs about others' ambiguity attitudes are highly, though imperfectly, correlated with their own attitudes toward ambiguity (Spearman's $\rho=0.50, p=0.009$, Pearson correlation coefficient $=0.61$ ). Two outliers believing that others' priors on the ambiguous event were below 0.12 , and thus unreasonably extreme, are excluded when conducting these tests. 


\section{E Experimental Instructions}

\section{General}

In this experiment you can earn money with the decisions you make. Your earnings may also depend on chance events and the decisions of other participants. At the end of the experiment you will be paid out in cash individually and confidentially. In order to ensure the highest level of anonymity and confidentiality, the payment will be carried out by a person that is not involved in this research project. The experimenters cannot link your earnings and decisions to your identity in any way. During the experiment you are not allowed to communicate in any other way than described in the instructions. If you have any questions please raise your hand. An experimenter will then come to you and answer your questions in private. The experiment consists of three parts. You will receive the instructions of a part only after the previous part has ended.

\section{Part 1}

In the first part of the experiment you will be randomly matched into groups of three participants, which will be labeled with the letters A, B and C. In this part of the experiment the B and C members of a group are asked to independently perform a task that involves correctly positioning sliders on a bar. Below you can see the representation of a slider in the initial position a) and in the correct position b), which is always in the middle of the bar. The slider is positioned correctly if the number that shows up to the right of the slider equals 50 .

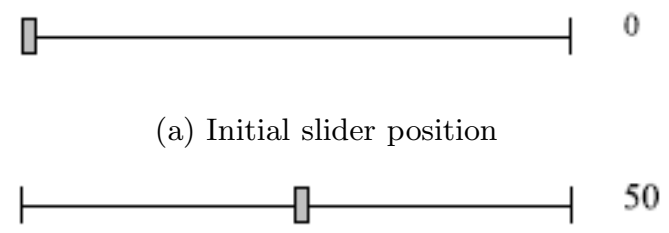

(b) Correct slider position

Figure E.1: Examples of slider positions

For each correctly positioned slider 0.25 Euro are credited. There are a total of 32 sliders to be positioned in 6 minutes time, so that $\mathrm{B}$ and $\mathrm{C}$ can be credited up to 8 Euro each. After the 6 minutes are over, the credit accumulated by B and C, who are in the same group, is deposited in a joint group account. Each member of a group (A, B and C) is then informed about the total 
amount in the joint account of their group. A also receives information about how many sliders were correctly positioned by $\mathrm{B}$ and $\mathrm{C}$ members in her or his group.

The task of $\mathbf{A}$ and earnings determination for A, B, and C: Person A earns money for performing a task, which is described below. At the end of the experiment, the earnings of A will be publicly and randomly determined by drawing a card from a stack of numbered cards. The earnings of A can be 4.-, 6.-, 10.- or 12.- Euro and each of these earnings are equally likely. Notice that the earnings of $\mathrm{A}$ only depend on chance. In particular, the earnings of $\mathrm{A}$ do in no way depend on the decisions taken by A. Also notice that the earnings of A are not taken from the joint account.

The task of A is to divide the amount of money in the joint account between B and C. A is asked to make a division in 7 different decision situations. At the end of the experiment one out of the 7 decisions will be randomly selected to determine $\mathrm{B}$ and $\mathrm{C}$ earnings. Each decision situation is independent and equally likely to be the one that determines the earnings of $\mathrm{B}$ and $\mathrm{C}$. Therefore, person A should carefully consider each decision and make each decision in isolation.

The 7 decision situations differ in the way the amount of money assigned to $\mathrm{B}$ and $\mathrm{C}$ translates into earnings for $\mathrm{B}$ and $\mathrm{C}$. The table below summarizes the 7 decision situations and shows how the earnings of $\mathrm{B}$ and $\mathrm{C}$ are determined in each decision situation. Notice that during the experiment the 7 decision situations will appear in random order. Please have a look at it.

\begin{tabular}{llr}
\hline Decision & Earnings of B & Earnings of C \\
\hline \hline 1 & allocation to B & allocation to C \\
2 & $20 \%$ chance 5 times allocation to B, $80 \%$ times 0 & allocation to C \\
3 & $50 \%$ chance 2 times allocation to B, $50 \%$ times 0 & allocation to C \\
4 & $80 \%$ chance 1.25 times allocation to B, $20 \%$ times 0 & allocation to C \\
5 & $50 \%$ chance 1.5 times allocation to B, $50 \%$ times 0.5 times allocation to B & allocation to C \\
6 & unknown chance 2 times allocation to B, unknown chance 0 & allocation to C \\
7 & unknown chance 1.5 times allocation to B, unknown chance 0.5 times allocation to B & allocation to C \\
\hline
\end{tabular}

We will now explain each decision situation in detail.

If, at the end of the experiment, decision situation 1 is selected to matter for payment then the earnings of $\mathrm{B}$ are equal to the allocation to $\mathrm{B}$ and the earnings of $\mathrm{C}$ are equal to the allocation to $\mathrm{C}$. 
If, at the end of the experiment, decision situation 2 is selected to matter for payment the final earnings of B depend on the amount of Euro allocated to B and on a chance event. The chance event will be the public drawing of a card from a stack of 100 cards numbered from 1 to 100. If a card with a number from 1 to 20 will be drawn then the earnings of B will be 5 times the money allocated to B (i.e., 500\% of the allocation to B). If a number from 21 to 100 will be drawn then the earnings of B will be 0 Euro. In other words, with $20 \%$ chance the earnings of B will be 5 times the allocation to $\mathrm{B}$ and with $80 \%$ chance the earnings of $\mathrm{B}$ will be 0 Euro. The earnings of $\mathrm{C}$ are equal to the allocation to $\mathrm{C}$.

If, at the end of the experiment, decision situation 3 is selected to matter for payment the final earnings of B depend on the amount of Euro allocated to B and on a chance event. The chance event will the public drawing of a card from a stack of 100 cards numbered from 1 to 100 . If a card with a number from 1 to 50 will be drawn then the earnings of $\mathrm{B}$ will be 2 times the allocation to B (i.e. $200 \%$ of the allocation to B). If a number from 51 to 100 will be drawn then the earnings of B will be 0 Euro. In other words, with $50 \%$ chance the earnings of $\mathrm{B}$ will be 2 times the allocation to $\mathrm{B}$ and with $50 \%$ chance the earnings of $\mathrm{B}$ will be 0 Euro. The earnings of $\mathrm{C}$ are equal to the allocation to $\mathrm{C}$.

If, at the end of the experiment, decision situation 4 is selected to matter for payment the final earnings of B depend on the amount of Euro allocated to B and on a chance event. The chance event will the public drawing of a card from a stack of 100 cards numbered from 1 to 100. If a card with a number from 1 to 80 will be drawn then the earnings of $\mathrm{B}$ will be 1.25 times the allocation to B (i.e. $125 \%$ of the allocation to B). If a number from 81 to 100 will be drawn then the earnings of B will be 0 Euro. In other words, with $80 \%$ chance the earnings of B will be 1.25 times the allocation to B and with $20 \%$ chance the earnings of B will be 0 Euro. The earnings of $\mathrm{C}$ are equal to the allocation to $\mathrm{C}$.

If, at the end of the experiment, decision situation 5 is selected to matter for payment the final earnings of B depend on the amount of Euro allocated to B and on a chance event. The chance event will the public drawing of a card from a stack of 100 cards numbered from 1 to 100. If a card with a number from 1 to 50 will be drawn then the earnings of $B$ will be 1.5 times the allocation to B (i.e. $150 \%$ of the allocation to B). If a number from 51 to 100 will be drawn then the earnings of $\mathrm{B}$ will be 0.5 times the allocation to B (i.e. $50 \%$ of the allocation to B). In other words, with $50 \%$ chance the earnings of B will be 1.5 times the allocation to $\mathrm{B}$ and with $50 \%$ chance the earnings of $\mathrm{B}$ will be 0.5 times the allocation to $\mathrm{B}$. The earnings of $\mathrm{C}$ are equal to the allocation to $\mathrm{C}$. 
If, at the end of the experiment, decision situation 6 is selected to matter for payment the final earnings of B depend on the amount of Euro allocated to B and on a chance event. The experimenters will first randomly select black or red to be the winning color. The chance event will then be the public drawing of a card from a stack of 100 cards which are black or red. The total number of red and black cards sums up to 100, but neither A nor B nor $\mathrm{C}$ nor the experimenters know how many red cards and how many black cards are in the stack. If a card with the winning color is drawn the earnings of B will be 2 times the allocation to B (i.e. $200 \%$ of the allocation to B). If a card with the losing color is drawn then the earnings of $\mathrm{B}$ will be 0 Euro. In other words, with an unknown chance the earnings of $\mathrm{B}$ will be 2 times the allocation to $\mathrm{B}$ and with an unknown chance the earnings of $\mathrm{B}$ will be 0 Euro. The earnings of $\mathrm{C}$ are equal to the allocation to $\mathrm{C}$.

If, at the end of the experiment, decision situation 7 is selected to matter for payment the final earnings of B depend on the amount of Euro allocated to B and on a chance event. The experimenters will first randomly select black or red to be the winning color. The chance event will then be the public drawing of a card from a stack of 100 cards which are black or red. The total number of red and black cards sums up to 100, but neither A nor B nor C nor the experimenters know how many red cards and how many black cards are in the stack. If a card with the winning color is drawn the earnings of $\mathrm{B}$ will be 1.5 times the allocation to $\mathrm{B}$ (i.e. $150 \%$ of the allocation to B). If a card with the losing color is drawn then the earnings of $\mathrm{B}$ will be 0.5 times the allocation to B (i.e. $50 \%$ of the allocation to B). In other words, with an unknown chance the earnings of $\mathrm{B}$ will be 1.5 times the allocation to B and with an unknown chance the earnings of $\mathrm{B}$ will be 0.5 times the allocation to $\mathrm{B}$. The earnings of $\mathrm{C}$ are equal to the allocation to $\mathrm{C}$.

If you have any question please raise your hand and an experimenter will come to answer your question in private. In the following you are asked a few questions that will help us assessing your understanding of the decision situations described above. Please fill in the missing figures. Note, that in these questions we are not interested in the actual numbers you fill in but only if you fill them in correctly. During the experiment you will have the possibility to use a calculator by clicking on the icon in the bottom right corner of the screen. When you are ready please raise your hand and an experimenter will come to you to check your answers. Once you are ready please wait quietly.

Consider decision situation 3 and assume that the total in the joint account is 16 Euro. If A assigns ... Euro to $\mathrm{C}$ and ... Euro to B, then this means that with...\% chance B earns .... Euro 
and with ...\% chance ... Euro. C earns ... Euro.

Consider decision situation 5 and assume that the total in the joint account is 15 Euro. If A assigns ... Euro to $\mathrm{C}$ and ... Euro to B, then this means that with ...\% chance B earns ... Euro and with ...\% chance ... Euro. C earns ... Euro.

Consider decision situation 7 and assume that the total in the joint account is 12 Euro. If A assigns ... Euro to $\mathrm{C}$ and ... Euro to B, then this means that with ... \% chance B earns ... Euro and with ...\% \% chance .... Euro. C earns .... Euro.

\section{Part 2}

You are now going to make a series of decisions. These decisions will not influence your earnings from the first part of the experiment, nor will the decisions you made in the first part of the experiment influence the earnings from this part. Furthermore, the decisions you are going to make will only influence your own earnings.

You will be confronted with 12 decision situations. All these decision situations are completely independent of each other. A choice you made in one decision situation does not affect any of the other following decision situations.

Each decision situation is displayed on a screen. The screen consists of 20 rows. You have to decide for every row whether you prefer option A or option B. Option A is the same for every row in a given decision situation, while option B takes 20 different values, one for each row. Note that within a decision situation you can only switch once from option B to option A: if you switch more than once a warning message will appear on the screen and you will be asked to change your decisions. By clicking on NEXT you will see some examples screens of decision situations.

This is a screen shot of a typical decision situation that you are going to face. You are not asked to make choices now! Please have a careful look. Thereafter click on NEXT to proceed. 


\begin{tabular}{|c|c|c|c|}
\hline & 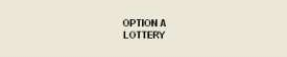 & vasurchoure & 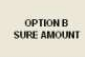 \\
\hline 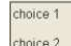 & & Arro & 16. \\
\hline chocice 2 & & A res & 155.40 \\
\hline 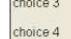 & & in & 14.80 \\
\hline chocece 5 & & 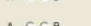 & (2) \\
\hline |chocece 6 & & 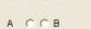 & 13. \\
\hline |chocere 7 & With 25\% chance you receive 16. Eurro, & $A c r e$ & 1240 \\
\hline |chocese 8 & with 75\% chance you receive 4.-Euro. & & 11.80 \\
\hline Cholice 9 & & $\operatorname{Acc} B$ & 11.20 \\
\hline Etonce 10 & & $\cdots$ & 10.6 \\
\hline |chocese 11 & & $\mathrm{~A}, \mathrm{Cr}$ & 10. \\
\hline chace 12 & & $A \cos$ & 940 \\
\hline Choloce 13 & & A ors & 8.80 \\
\hline Choce 14 & & 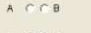 & 8.20 \\
\hline Erocece 15 & & A & 7.60 \\
\hline 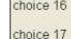 & & A & 7. \\
\hline Chacke 18 & & $A \operatorname{crs}$ & 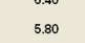 \\
\hline Chocece 19 & & $\operatorname{Arcos}$ & 5.20 \\
\hline cholice 20 & & $A \sim r$ & 4.60 \\
\hline
\end{tabular}

This is another screen shot of a typical decision situation that you are going to face. If you want to review the previous example click on BACK, otherwise click on NEXT to proceed.

\begin{tabular}{|c|c|c|c|}
\hline & $\begin{array}{l}\text { oppown } \\
\text { Lortery }\end{array}$ & YOUR CHOKE & 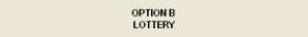 \\
\hline choice 1 & & $A \subset r \theta$ & 12. Euro for sure \\
\hline choice 2 & & $\operatorname{Arc} \theta$ & 12. Euro with $95 \%$ chance, 4. Euro with $5 \%$ chance \\
\hline choice 3 & & $A \subset C B$ & 12. Euro with $90 \%$ chance, 4 - Euro with $10 \%$ chance \\
\hline choice 4 & & $\operatorname{Acca} \theta$ & 12. Euro with $85 \%$ chance. 4 . Euro with $15 \%$ chance \\
\hline choice 5 & & $\operatorname{Acco}$ & 12. Euro with $80 \%$ chance, 4. Euro with $20 \%$ chance \\
\hline choice 6 & & A cro & 12. Euro with $75 \%$ chance, 4 - Euro with $25 \%$ chance \\
\hline choice 7 & With unknown chance you either & $A \subset r B$ & 12. Euro with $70 \%$ chance, 4 - Euro with $30 \%$ chance \\
\hline choice 8 & & $A r r \theta$ & 12. Euro with $65 \%$ chance. 4 - Euro with $35 \%$ chance \\
\hline choice 9 & & $A r C \theta$ & 12. Euro with $60 \%$ chance. 4. Euro with $40 \%$ chance \\
\hline choice 10 & & $A<r a$ & 12. Euro with $55 \%$ chance, 4. Euro with $45 \%$ chance \\
\hline choice 11 & & A $C r B$ & 12- Euro with $50 \%$ chance, 4- Euro with $50 \%$ chance \\
\hline choice 12 & & $A \subset r a$ & 12. Euro with $45 \%$ chance. 4 - Euro with $55 \%$ chance \\
\hline choice 13 & & $A \subset C B$ & 12. Euro with $40 \%$ chance. 4. Euro with $60 \%$ chance \\
\hline choice 14 & & $A \subset C \theta$ & 12. Euro with $35 \%$ chance. 4 . Euro with $65 \%$ chance \\
\hline choice 15 & $?$ & A cre & 12. Euro with $30 \%$ chance. 4. Euro with $70 \%$ chance \\
\hline choice 16 & & $A C r B$ & 12. Euro with $25 \%$ chance, 4 - Euro with $75 \%$ chance \\
\hline choice 17 & & $A \subset C B$ & 12- Euro with $20 \%$ chance, 4 - Euro with $80 \%$ chance \\
\hline choice 18 & & $A \subset C B$ & 12. Euro with $15 \%$ chance. 4 . Euro with $85 \%$ chance \\
\hline choice 19 & & $A C r a$ & 12. Euro with $10 \%$ chance. 4. Euro with $90 \%$ chance \\
\hline choice 20 & & $A \subset C B$ & 12. Euro with $5 \%$ chance. 4. Euro with $95 \%$ chance \\
\hline
\end{tabular}

Determination of earnings. At the end of the experiment one of the 12 decision situations will be randomly selected with equal probability. Once the decision situation is selected, one of the 20 rows in this decision situation will be randomly selected with equal probability. The choice you have made in this specific row will determine your earnings.

Consider, for instance, the first screen shot that you have seen. Option A gives you a 25\% chance to earn 16.- Euro and a $75 \%$ chance to earn 4.- Euro. Option B is always a sure amount that ranges from 16.- Euro in the first row, to 4.60 Euro in the 20th row. Suppose that the 12th row is randomly selected. If you would have selected option B, you would receive 9.40 Euro. If, 
instead, you would have selected option A, the outcome of the lottery determines your earnings. At the end of the experiment the lottery outcome will be publicly determined by randomly drawing a card from a stack of numbered cards.

Consider now the second screen shot that you have seen. Option A gives you an unknown chance to earn 12.- Euro and an unknown chance to earn 4.- Euro. Option B is always a lottery that gives you different chances to earn 12.- Euro or 4.- Euro. Suppose that the 10th row is randomly selected. If you would have selected option B, you would receive 12.- Euro with 55\% chance and 4.- Euro with $45 \%$ chance. If, instead, you would have selected option A, a stack of red and black cards would be used at the end of the experiment to determine whether you earn 12.- Euro or 4.- Euro. This stack of cards will be the same that has been described in part 1: recall that the exact number of black cards and the exact number of red cards in the stack are unknown to you and to us as well. You would earn 12.- Euro if a card of the winning color is drawn and 4.- Euro otherwise.

Please note that each decision situation has the same likelihood to be the one that is relevant for your earnings. Therefore, you should view each decision independently and consider all your choices carefully. If you like to, you can review the examples screens once more by clicking on BACK. If you have any questions please raise your hand. When you are ready, please press the BEGIN button below.

\section{Part 3}

In the following you are asked to estimate the choices made by one of your group members in 6 decision situations of the second part of the experiment. After having made these estimates you will answer a questionnaire and then the experiment will be over.

You are going to be randomly matched to one of your group members. For a certain decision situation you are asked to indicate which is the last row where you believe your matched group member chooses option B before switching to option A. You earn 1 Euro if you correctly indicate the switching point of your matched group member in a certain decision situation. Therefore, you can earn up to 6 Euro in total. If the true switching point of your matched group member is different from the point you indicated you earn nothing.

If you do not want to indicate a single switching point you can indicate a range of values where you think the switching point of your matched group member lies. If the true switching point lies in this range of values you will earn a positive amount smaller than 1 Euro. The exact amount you earn is calculated according to a formula. The formula captures the idea that earnings 
are inversely related to the length of the interval you indicate. This means that the larger the interval you indicate the smaller your potential earnings are. This formula also guarantees that your earnings are maximized if you truthfully indicate your estimate. If the true switching point of your counterpart lies outside the interval you indicate you earn nothing. Please click on NEXT to view an example.

This is a screen shot of a typical screen that you are going to see.

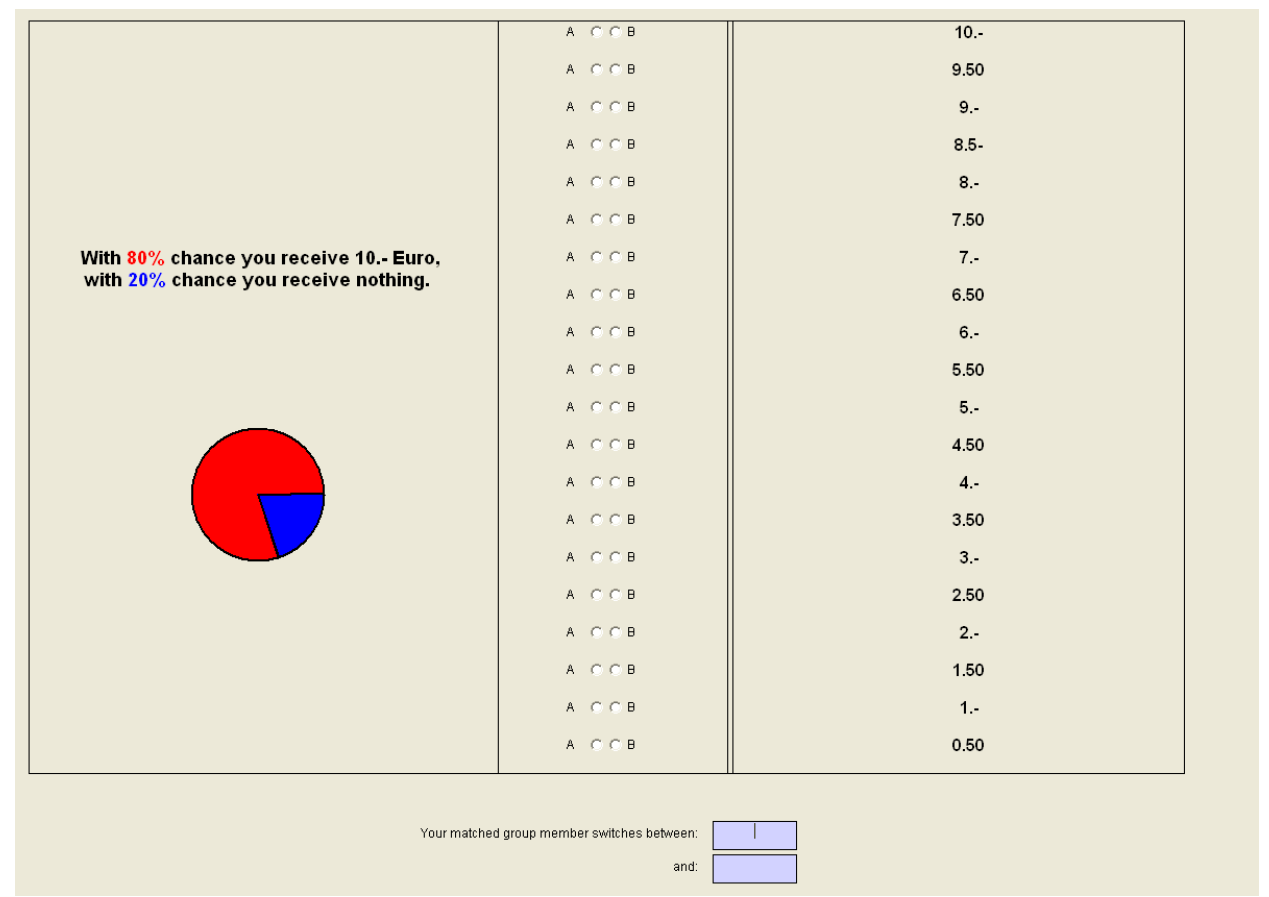

Assume, for instance, that you believe that your matched group member chooses option B for the last time when option B is equal to 6.- Euro. In such a case, you would type the number 6 in both boxes at the bottom of the screen.

Assume now that you believe that your matched group member may switch from option B to option A when option B takes any value between 8.- Euro and 4.50 Euro. In such a case, you would type the number 8 in the first box and the number 4.50 in the second box. Notice that you earn nothing if you type in two values that cover all possible switching points, in this case if you type in 10 and 0.50 .

If you have any question please raise your hand. Otherwise click on NEXT to proceed.

This is another screen shot of a typical screen that you are going to face. 


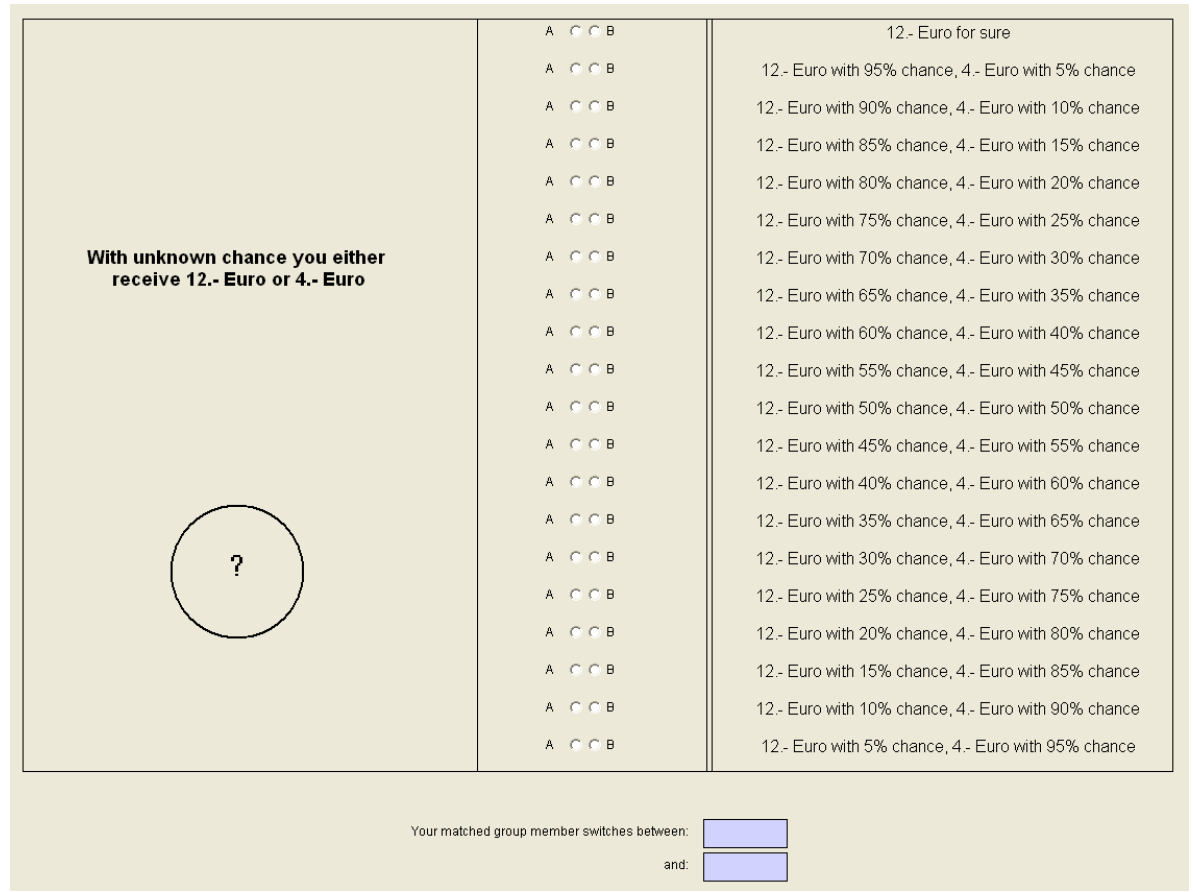

Assume, for instance, that you believe that your matched group member chooses option B for the last time when option B gives a chance of $40 \%$ to win 12.- Euro. In such a case, you would type the number 40 in both boxes at the bottom of the screen.

Assume now that you believe that your matched group member switches from option B to option A when the winning chance of option B is between $70 \%$ and $25 \%$. In such a case, you would type the number 70 in the first box and the number 25 in the second box. Notice that you earn nothing if you type in two values that cover all possible switching points, that is if you type in 100 and 5.

If you have any question please raise your hand. If you want to review the previous examples once more click on BACK. Otherwise, click on BEGIN to start the third part of the experiment. 